\title{
Hydraulic fracture propagation in a heterogenous stress field in crystalline rock mass
}

\author{
Nathan Dutler ${ }^{1}$, Benoît Valley ${ }^{1}$, Valentin Gischig ${ }^{2}$, Linus Villiger ${ }^{3}$, Hannes Krietsch ${ }^{3}$, \\ Joseph Doetsch ${ }^{3}$, Bernard, Brixel ${ }^{3}$, Mohammadreza Jalali ${ }^{4}$, Florian Amann ${ }^{4}$ \\ ${ }^{1}$ Center for Hydrogeology and Geothermics (CHYN), University of Neuchâtel, Switzerland \\ ${ }^{2}$ CSD Engineers, Bern, Switzerland \\ ${ }^{3}$ Department of Earth Science, ETH Zurich, Switzerland \\ ${ }^{4}$ Department of Engineering Geology and Hydrogeology, RWTH Aachen, Germany
}

\section{Contents of this file}

Text S1: Pressure vs. Flow-rate analysis

Text S2: Transmissivity values

Text S3: Detailed observation of tilt, strain and pressure

Text S4: Summary of the MF injection pressure and seismic characteristics

Text S5: Fracture orientation determination from borehole logging and seismic plane analyses

Text S6: Experimental summary cards

Text S7: Reference

Figure S1: Example of breakdown pressure, $\mathrm{P}_{\mathrm{b}}$, fracture reopening pressure, $\mathrm{P}_{\mathrm{r}}$, and instantaneous shut-in pressure, ISIP, inclusive evaluation of the pressure-controlled step test

Figure S2: Pressure vs Flow-rate for final injectivity and jacking pressure

Figure S3: Time series of tilt measurement for experiment HF6/HF1 and HF8/HF5

Figure S4: Selected time series and overview of the FBG strain signals for experiment HF6/HF1 and HF8/HF5

Figure S5: Selected time series of pressure response are presented for experiment HF6/HF1 and HF8/HF5

Figure S6: Overview of the injection interval locations for the experimental summary cards presented hereinafter

Figure S7: Summary HF1

Figure S8: Summary HF3

Figure S9: Summary HF2

Figure S10: Summary HF5

Figure S11: Summary HF6

Figure S12: Summary HF8

Figure S13: Summary MF1

Figure S14: Summary MF2

Figure S15: Summary MF3

Figure S16: Summary MF4 
Figure S17: Summary MF5

Figure S18: Summary MF6

Figure S19: Summary MF7

Table S1: Summary of jacking pressure and injectivity values using different methods

Table S2: Transmissivity, storativity and hydraulic head

Table S3: Overview of injection pressure, fluid injection and seismic characteristics of the seven hydraulic fracturing experiments during stress characterization phase

Table S4: Summary of injection pressure and fluid injection of the four hydraulic fracturing tests from borehole $\mathrm{SBH} 1$

Table S5: Trace description form geophysical borehole logging incl. trace fit and plane fit through located micro-seismic events 


\section{S1: Pressure vs. Flow-rate analysis}

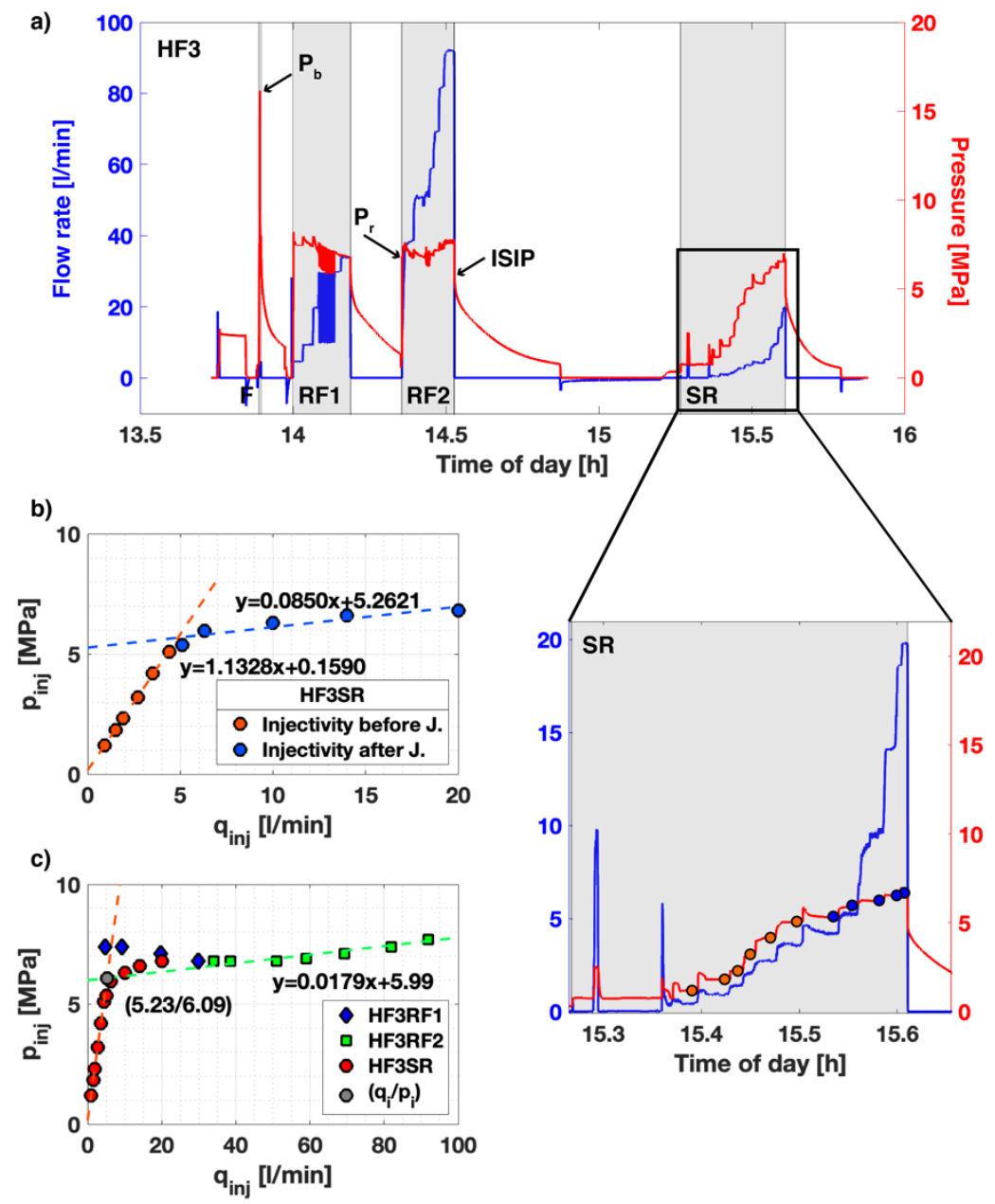

Figure S1: a) Testing procedure for HF3 experiment, with breakdown pressure, $P_{b}$, fracture reopening pressure, $P_{r}$, and instantaneous shut-in pressure, ISIP, inclusive pressure-controlled step tests with evaluated flowrate ( $\left.q_{i n j}\right)$ vs. injection pressure ( $\left.p_{\text {inj }}\right)$ points. b) The $q_{\text {inj }}$ Vs. $p_{\text {inj }}$ plot shows the final matrix injectivity (reverse of the slope of the orange dashed line) and the jacking pressure from the SR cycle (intersection of the blue dashed line with y-axis). c) The $q_{\text {inj }}$ vs. $p_{\text {inj }}$ point at pseudo steady-state from the second refrac cycle RF2 are included to estimate the fracture injectivity (reverse of the slope of the green dashed line) and the jacking pressure from two different methods.

We use pressure vs flow rate analysis to extract diagnostic injection parameters including the jacking pressure (JP). Since the best way of determining such pressure is debated in the literature, we describe here the approach with use in our analyses. We first use the injection HF3 to exemplify our approach (Fig. S1). We apply then the approach systematically to all our tests (Fig S2).

The first step of our analyses is to determine conditions close to steady state. We did this on flowcontrolled injection (RF1 and RF2 cycles) and pressure-controlled injection (SR). In both case we extracted the pressure pinj and the flow qinj at the point just prior the next step of flow or pressure is initiated (Fig. S1 a, zoomed frame). In our tests, we typically waited long enough to have an almost stabilized pressure and flow prior initiating the next step and we assume then the conditions are in quasi-steady state.

We report the data in a pinj vs. qinj diagram including only data from the SR cycle (Fig. S1b) or data from both SR and RF cycles (Fig. S1c). Typically, these data form a bilinear pattern. At low pressures, the determination of a linear trend is straight forward (orange dashed line on Fig. S1b and c). The inverse of the slope of this linear relationship corresponds to what will be referred to as the injectivity index before jacking $\left(\mathrm{II}_{\mathrm{b}}\right)$ given in $\mathrm{I} / \mathrm{min} / \mathrm{MPa}$ and it is equal for $\mathrm{HF3}$ at $0.88 \mathrm{l} / \mathrm{min} / \mathrm{MPa}$. 
a)

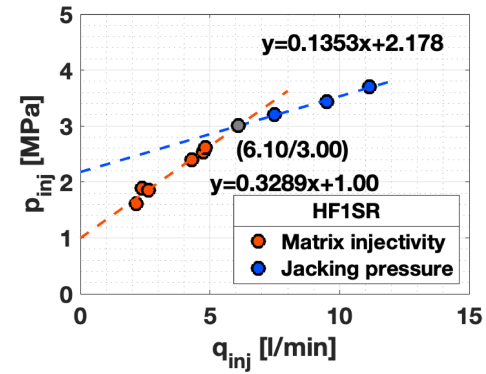

b)
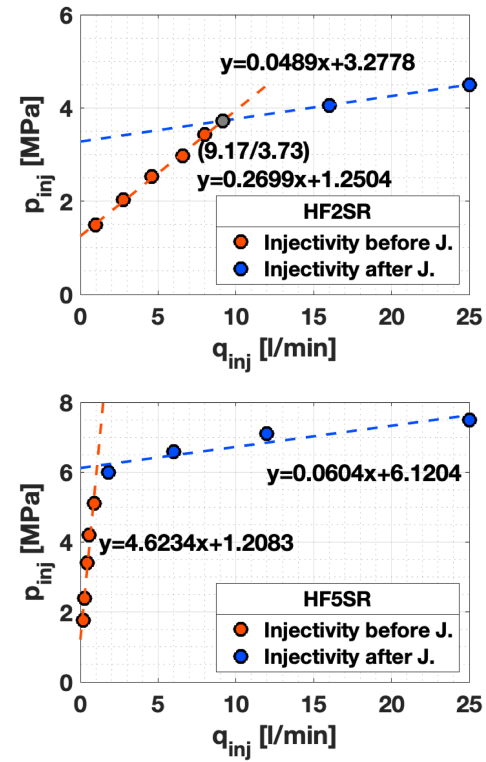

d)

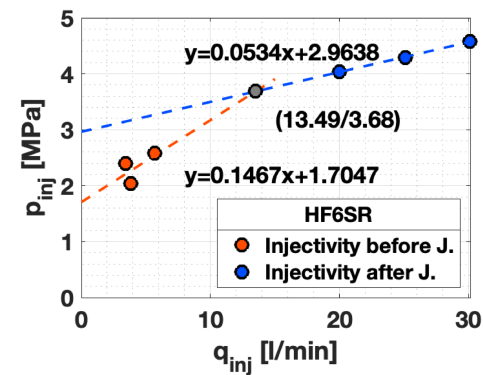

e)

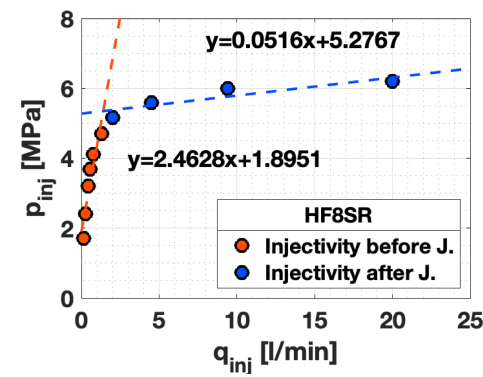

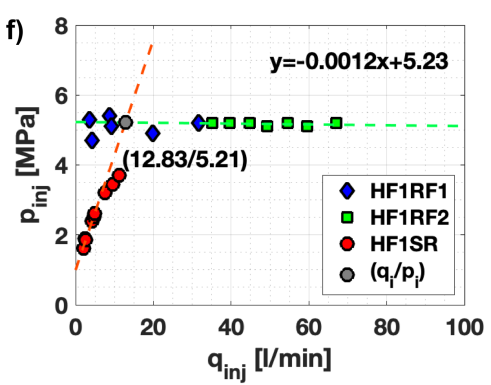

g)
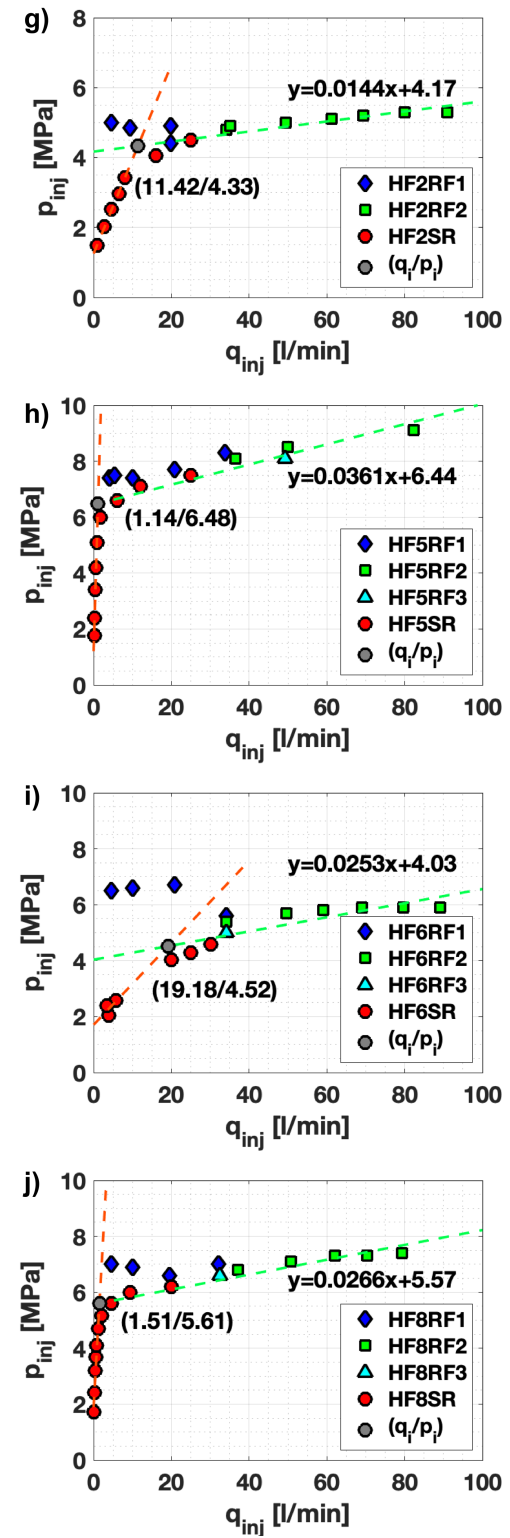

Figure S2: a-e) The $q_{i n j}$ vs. $p_{\text {inj }}$ plots show the final injectivity (inverse of the slope of the orange dashed line) and the jacking pressure from the SR cycle for the HF tests. g-j) The $q_{i n j}$ vs. $p_{\text {inj }}$ point at pseudo steady state from the second refrac cycle RF2 are included to estimate the fracture injectivity (inverse of the slope of the green dashed line) and the jacking pressure from two different methods.

At high pressure the injectivity increases because the fracture opens (Doe \& Korbin, 1987). The linearity of the high-pressure data point is less evident as it depends on what data are included. We took the approach to determine the linear trend including the SR data only (Fig. S1b) and both the SR and RF data (Fig. S1c). The linear trend is typically flatter when all data are included. The inverse of the slope of these linear relationships is the injectivity after jacking $\left(\mathrm{II}_{\mathrm{a}}\right)$, where we define a low value $\left(\mathrm{II}_{\mathrm{a}}^{\mathrm{min}}\right)$ using only SR data and a high value $\left(\mathrm{II}_{\mathrm{a}}{ }^{\mathrm{max}}\right)$ using all data. 
We define the jacking pressure (JP) following the approach of Rutqvist \& Stephansson (1996) by the intersection of the high-pressure trend line with the zero-flow ordinate. Since depending on what data, we included (only SR or all data), we defined two different high-pressure trend line, we also have to intersection with the zero-flow ordinate: $J P_{\min }$ using only SR data and $J P_{\max }$ using all data.

As an alternate diagnostic parameter, we report also - following Hartmaier et al. (1998) - the intersection point $\mathrm{q}_{\mathrm{i}} / \mathrm{p}_{\mathrm{i}}$ between the low- and high-pressure trend lines using all data.

The $p_{\text {inj }} v s q_{i n j}$ data for all other injection tests are presented in Fig. S2 and the diagnostic parameters are summarized in Table S1. For tests HF1, HF2 and HF6, the gradual change in slope of $p_{\text {inj }}$ vs $q_{\text {inj }}$ data would give an overestimate of the $p_{i}$ including all data points. Therefore, we used only the SR data to determine the point $q_{i} / p_{i}$ and the advantage is that $p_{i}$ is in the range of $J P_{\min }$ and $J P_{\max } . J P_{\max }$ are in the same range than $p_{i}$ for the other three tests. Therefore, no data were excluded.

The best estimate of jacking pressure depends actually on the $p_{\text {inj }}$ vs $q_{\text {inj }}$ curve. HF3, HF5 and HF8 show a strong bi-linear trend, where the change in the number of data points does not show a strong variation in a possible jacking pressure. Nevertheless, the smallest possible jacking was used to account for earliest variation in the hydraulic fracture aperture. We decided not to do so for test HF1, HF2 and HF8, as the bi-linear trend is less pronounced. The range between $\mathrm{JP}_{\min }$ and $J \mathrm{P}_{\max }$ is much bigger and a reliable midway between this two was found using the intersection method.

Table S1: The jacking pressure and injection index are estimated as described in the text. Values in red are the best estimate of jacking pressure for a specific test. "not considering the points from the cycle SR, would increase this value; *takes only the points into account from SR

\begin{tabular}{|c|c|c|c|c|c|c|c|}
\hline Test & $\begin{array}{l}J P_{\min } \\
{[\mathrm{MPa}]}\end{array}$ & $\begin{array}{l}J P_{\max } \\
{[\mathrm{MPa}]}\end{array}$ & $\begin{array}{l}\mathrm{II}_{\mathrm{b}} \\
{[\mathrm{I} / \mathrm{min} / \mathrm{MPa}]}\end{array}$ & $\begin{array}{l}\mathrm{II}_{\mathrm{a}}^{\min } \\
{[\mathrm{I} / \mathrm{min} / \mathrm{MPa}]}\end{array}$ & $\begin{array}{l}\mathrm{II}_{\mathrm{a}}^{\max } \\
{[\mathrm{I} / \mathrm{min} / \mathrm{MPa}]}\end{array}$ & $\begin{array}{l}q_{i} \\
{[1 / \min ]}\end{array}$ & $\begin{array}{l}p_{i} \\
{[\mathrm{MPa}]}\end{array}$ \\
\hline HF1 & 2.18 & 5.23 & 3.040 & 7.39 & $28.74^{\prime \prime}$ & $6.10^{*}$ & $3.00 *$ \\
\hline HF2 & 3.28 & 4.17 & 3.693 & 20.45 & 69.44 & $9.17^{*}$ & $3.73 *$ \\
\hline HF3 & 5.26 & 5.99 & 0.882 & 9.81 & 55.87 & 5.23 & 6.09 \\
\hline HF5 & 6.12 & 6.44 & 0.206 & 14.63 & 27.70 & 1.14 & 6.48 \\
\hline HF6 & 2.96 & 4.03 & 2.774 & 18.69 & 39.53 & $13.49 *$ & $3.68 *$ \\
\hline HF8 & 5.28 & 5.57 & 0.347 & 15.69 & 37.59 & 1.51 & 5.61 \\
\hline
\end{tabular}

\section{S2: Transmissivity values}

The transmissivity of each tested interval was determined prior hydraulic fracturing by analyzing a Pulse injection (PI) and after the injection by converting the injectivity determined during the SR cycle to transmissivity assuming steady-state radial flow regime (De Marsily, p 150) and by performing 3 month later Constant Head Injection (CHI) tests.

All estimates are summarized in Table $\mathbf{S 2}$. The transmissivity estimated from injectivity are typically 2 to 3 orders of magnitude higher than the one estimated by $\mathrm{CHI}$ tests. We attribute these differences to:

- The $\mathrm{CHI}$ depends only on one constant pressure. Injectivity is measured at different pressures.

- The increase in pressure during injectivity measurement can influence the fracture compliance and fracture aperture. The assumption of radial flow is than violated.

- The step tests for injectivity uses many steps where the pressure was progressively increased. If the time for a single step is too short, the results can include values with non-pseudo steady state flow.

For these reasons, we assume that the transmissivity obtained from both methods are relevant. Depending on the injection pressure, the transmissivity increases due to an increase in the hydraulic aperture. 
Table S2: Transmissivity estimated from PI tests before and from CHI tests and injectivitiy after the HF experiments.

\begin{tabular}{|c|c|c|c|c|c|}
\hline \multirow{2}{*}{$\begin{array}{l}\text { OD } \\
\frac{0}{D} \\
\frac{D}{D} \\
\frac{0}{D}\end{array}$} & \multirow{2}{*}{$\begin{array}{l}\frac{\bar{g}}{\tilde{g}} \\
\underline{\underline{D}}\end{array}$} & \multirow{2}{*}{$\begin{array}{c}\text { Depth } \\
{[\mathrm{m}]}\end{array}$} & $\begin{array}{c}\text { before } \\
\text { HF }\end{array}$ & \multicolumn{2}{|c|}{ after HF } \\
\hline & & & $\begin{array}{c}\mathrm{T}_{\mathrm{Pl}} \\
{\left[\mathrm{m}^{2} / \mathrm{s}\right]}\end{array}$ & $\begin{array}{c}\mathrm{T}_{\mathrm{CHI}} \\
{\left[\mathrm{m}^{2} / \mathrm{s}\right]}\end{array}$ & $T_{i n j}\left[m^{2} / s\right]$ \\
\hline \multirow{4}{*}{$\sum_{\underline{1}}^{\bar{z}}$} & HF1 & 40.5 & $3.1 \mathrm{E}-13$ & $1.9 \mathrm{E}-09$ & $1.3 \mathrm{E}-07$ \\
\hline & HF2 & 36.3 & 3.0E-13 & $2.5 \mathrm{E}-09$ & $1.6 \mathrm{E}-07$ \\
\hline & HF3 & 20.3 & $4.0 \mathrm{E}-13$ & $2.1 \mathrm{E}-10$ & $3.9 \mathrm{E}-08$ \\
\hline & HF5 & 14.5 & $2.3 \mathrm{E}-13$ & $2.0 \mathrm{E}-10$ & 9.1E-09 \\
\hline \multirow{2}{*}{ 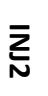 } & HF6 & 38.9 & - & $4.8 \mathrm{E}-07$ & $1.2 \mathrm{E}-07$ \\
\hline & HF8 & 15.7 & $5.7 \mathrm{E}-13$ & $3.6 \mathrm{E}-11$ & $1.5 \mathrm{E}-08$ \\
\hline
\end{tabular}

\section{S3: Detailed observation of tilt, strain and pressure}

Tilt:

- HF2 and HF1 are located next to the intersection of the S1 and S3 zone. Both experiments show similar tilt signals. HF6 is further away towards the AU tunnel and the water is injected in the $\mathrm{S} 1$ fracture network. The tiltmeters indicate a tensional and/or shearing signal related to the S1 zone.

- HF3 and HF8 are executed more or less at the same position in INJ1 and the other in INJ2 borehole. Therefore, the two signals are very similar and show small magnitudes. The flow shortcut toward an existing borehole during HF5 did not allow to store fluid in the fracture, such that the tilt signals are very small.

- We do not recognize changes in the tilt signal due to different fluid metrics. The location of the injection and the associated geological structures dominate the tilt signal. 


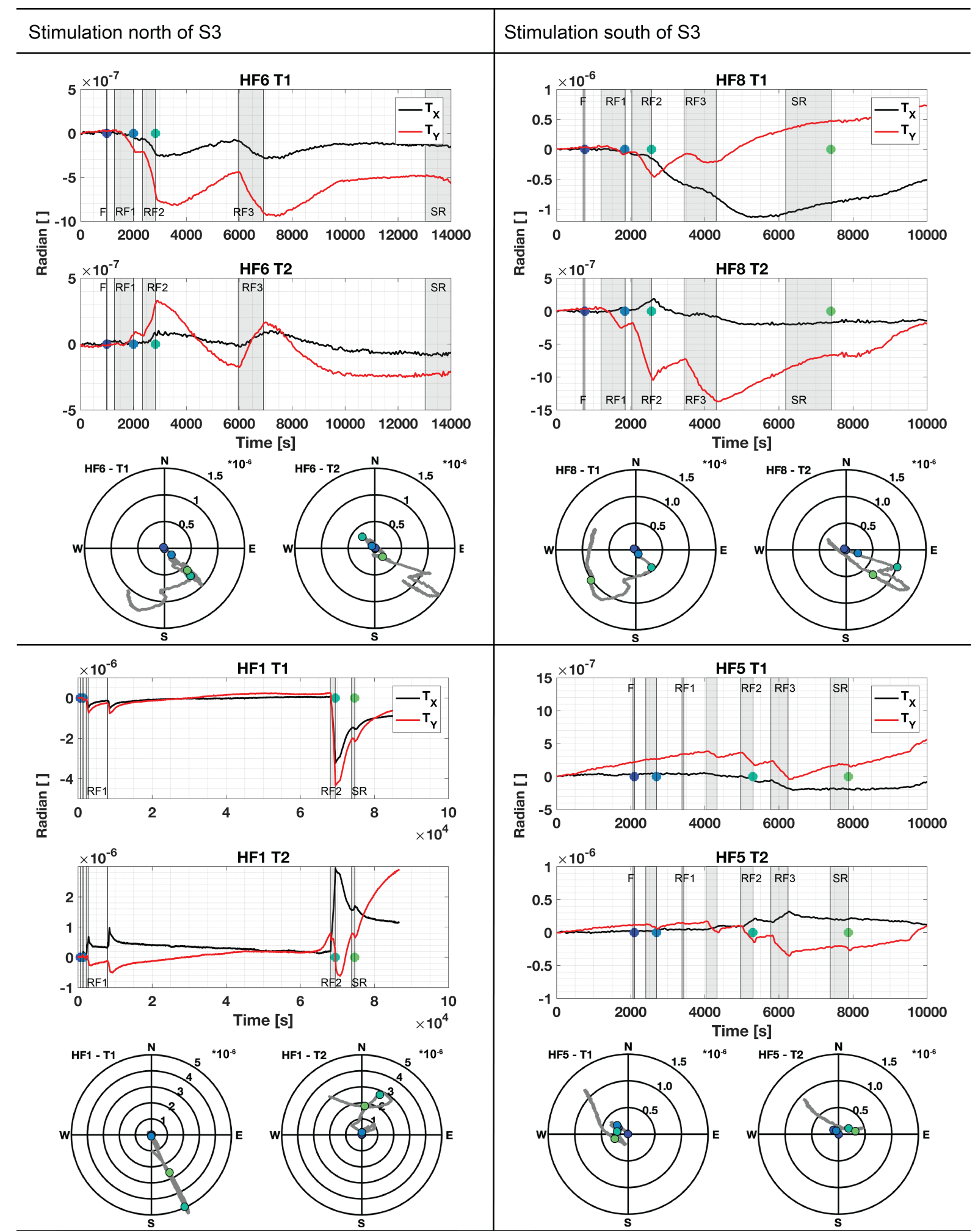

Figure S3: The time series of tilt meter T1 and T2 are presented for the experiment HF6/HF1 and HF8/HF5. The fluid injection time are named and indicated by the grey boxes. The color points at the end of fluid injection in the time series are presented in a polar plot. The circles correspond to the magnitude given in microradian.

Strain:

- HF2 and HF1 are next to the intersecting S1 and S3 zone have very similar strain signals. Especially in FBS2 and FBS3 borehole the FBG's behave similar and show comparable magnitudes at the end of refrac cycle RF2. The last two FBG sensors in the FBS1 borehole indicate a tensional signal during HF1, where only the last sensor reacts tensional during HF2. 
- The time series presented from test HF6 in FBS1 show the deepest three FBG sensors, where two of them show a tensional signal and the sensor at $42.2 \mathrm{~m}$ indicates compressional signal during RF2. At the end of the test, the sensor shows a relaxation drift. The FBG sensor at $23.3 \mathrm{~m}$ located along the $\mathrm{S} 1$ zone show a tensional signal and the signal from FBG sensor at $36.1 \mathrm{~m}$ shows a strong compressional signal. For test HF6, the sensor at $31.6 \mathrm{~m}$ depth presents more or less the change from tensional to compressional signal in the borehole FBS3 and vice versa for the tests HF1/HF2.

- The sensors from test HF8 at $22.35 \mathrm{~m}$ depth in FBS1 and at $20 \mathrm{~m}$ depth in FBS2 have the strongest tensional signal similar to the test HF3. The strain response during the first refrac cycle RF1 is delayed for test HF8 compared to test HF3. Note that the tensional signals are very localized comparing the sensors along the borehole (FBS1 and FBS2). The viscous fluid used during this test is amenable to form a single dominant hydraulic fracture.

- The time series presented from HF5 show a direct tensional signal in FBS1 (15.6 m) at the beginning of RF1, where the connection towards the geophysical borehole was established. Therefore, magnitudes reached for transient peak strain are much smaller compared to the tests HF3 and HF8. At the end of the test, when the injection packer was released, all the presented time series responded with a tensional or compressional change.

- Note, we decided to focus our data presentation on time series from tensional signals, as they can be indicators for fluid paths. 


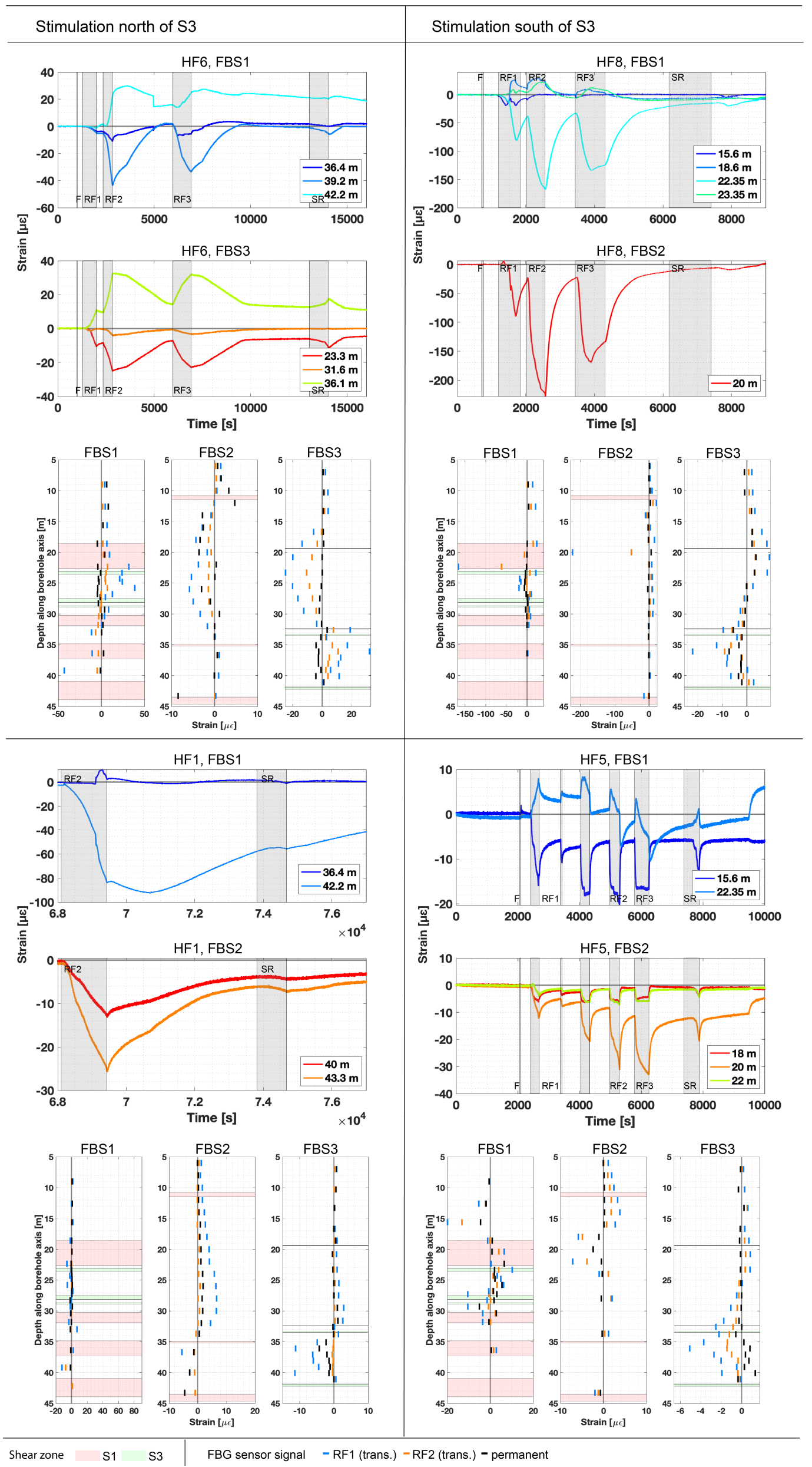


Figure S4: Selected time series and overview of the FBG strain signals for experiment HF6/HF1 and HF8/HF5. The fluid injection time is named and indicated by the grey boxes

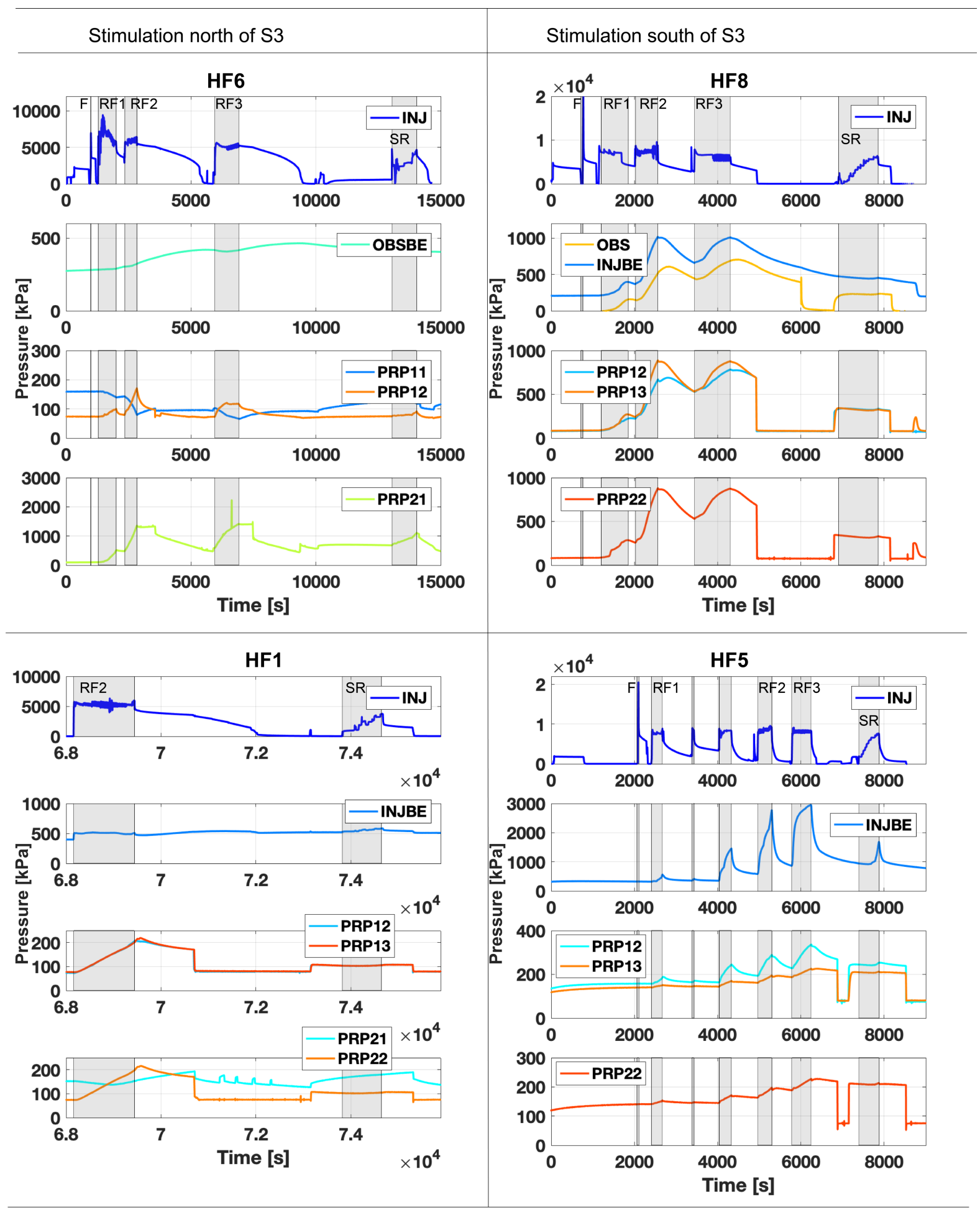

Figure S5: Selected time series of pressure response are presented for experiment HF6/HF1 and HF8/HF5. The fluid injection time is named and indicated.

Fracture fluid pressure observations:

- Test HF1 do not show strong responses in the observation intervals. Comparing PRP2-2 with test HF2 show a similar response during and after RF2. It is reaching the peak pressure with a delay. The response in PRP1-1 (S1) during the test HF1 was smaller than for PRP1-2 and PRP13 , both located in the S3 zone. All the presented PRP intervals show a very similar fracture 
fluid pressure response except PRP2-1. The interval below injection show very large pressure response during HF2 but none was observed during test HF1. The small fracture fluid pressure response towards East indicates a less connected fracture network.

- During test HF6, strong responses are recognized for interval PRP2-1. This interval shows an increase during injection with a delay reaching the peak and stabilizing until bleed-off. The signal observed in borehole interval PRP1-1, is very interesting. It shows a pressure release during injection and PRP1-2 an increase in the same range of magnitude. In addition, only a fracture fluid pressure signal is observed in the OBSBE. This actually tells us, that the related fracture from HF1/HF2 and HF6 injections are different and not related with each other and that the fractures connected to injection interval HF6 are as well connected to the densely fractured zone S3, but in a different way than for HF1/HF2.

- We observe smaller magnitudes during the HF8 experiment than for HF3. All the presented time series for the observation interval are very similar. It does not matter if the signal was observed in the PRP borehole or below the injection. For all PRP observation intervals and the INJBE we see a pseudo shut-in at the end of refrac cycle RF2. Only the observation interval (OBS) shows no pseudo shut-in and the longest delay time reaching the pressure peak. We noted that the signals for all observation points are very similar indicating an existing fluid path between all intervals. Therefore, we increase the connectivity and this leads to larger swept volume, which is a key factor for successful fracturing.

- The test HF5 shows small increase in pressure for the PRP observation intervals during injection. The INJBE interval has magnitudes up to $3 \mathrm{MPa}$, which seems to indicate a short-cut towards this interval. A packer sealing issue is unlikely as no seismicity is observed. The pressure increase observed in the interval INJBE, drives the fluid/pressure into the most conductive features in S3 and raise the pressure in the PRP intervals.

\section{S4: Summary of the MF injection pressure and seismic characteristics}

The event catalogue and the data from the injection location (e.g. flow rate and injection pressure) used in here, is published by Jalali et al. (2018) (direct link to the dataset: https://doi.org/10.3929/ethz-b-000217536). The in-situ test procedure and the test analysis followed the ISRM guideline (Haimson \& Cornet, 2003). The breakdown pressure was measured during the fraccycle. The instantaneous shut-in pressure (ISIP) was obtained during each cycle using the tangent method. The re-opening pressure $\left(P_{r}\right)$ was measured for the refrac cycle RF (Table S3) using the tangent method.

For the MF experiment the injected water was outside of the borehole measured with a flowmeter. The accumulation of the injected water corresponds to the injection volume $V_{i}$. The backflow was measured at the injection interval during venting. Thus, the fluid recovery $V_{r}$ is the total recovery for the MF experiments.

The earthquake catalogue has a calculated error ellipsoid with principle component direction for each event. An event was approved for the minifrac MF1, MF2 and MF3, when the maximum ellipsoid axis was equal or smaller than $2 \mathrm{~m}$. For the minifrac MF4 to MF7, this threshold value was set to $3 \mathrm{~m}$.

Table S3: Overview of injection pressure, fluid injection and seismic characteristics of the seven hydraulic fracturing experiments during stress characterization phase. All seven hydraulic fractures were propagated in multiple refracturing phases. Comparison of fracture breakdown pressure $\left(P_{c}\right)$, fracture reopening pressure $\left(P_{r}\right)$ and additional hydraulic test parameters $\left(V_{i}\right.$, injected volume; $V_{r}$, recovered volume) and localized AE event numbers. *MF5 indicate an insufficient sealing of the test section.

\begin{tabular}{lllllll}
\hline Stage No. & Experiment & $\mathbf{P}_{\mathbf{c}} \& \mathbf{P}_{\mathbf{r}}(\mathrm{MPa})$ & ISIP $(\mathrm{MPa})$ & $\mathbf{V}_{\mathbf{i}}(\mathbf{I})$ & $\mathbf{V}_{\mathbf{r}}(\mathbf{I})$ & Number of localized AE \\
\hline 1 & MF1-F & 23.4 & 8.5 & 1.1 & 0.15 & 3 \\
2 & MF1-RF1 & 7.6 & 8.4 & 1.8 & 0.2 & 24 \\
\hline
\end{tabular}




\begin{tabular}{|c|c|c|c|c|c|c|}
\hline 3 & MF1-RF2 & 7.6 & 8.1 & 3.3 & 0.2 & 29 \\
\hline \multirow[t]{2}{*}{4} & MF1-RF3 & - & 8.0 & 4.2 & 0.2 & 56 \\
\hline & & & & 10.4 & $7 \%$ & 112 \\
\hline 5 & MF2-F & 25.7 & - & 1.0 & 0.6 & 0 \\
\hline 6 & MF2-RF1 & 9.6 & 9.0 & 1.5 & 1.0 & 15 \\
\hline 7 & MF2-RF2 & 10.1 & 8.6 & 3.3 & 2.4 & 35 \\
\hline \multirow[t]{2}{*}{8} & MF2-RF3 & 10.3 & 8.8 & 4.2 & 3.2 & 58 \\
\hline & & & & 10.0 & $72 \%$ & 108 \\
\hline 9 & MF3-F & 26.1 & - & 0.5 & 0.35 & 3 \\
\hline 10 & MF3-RF1 & 11.55 & 9.2 & 1.6 & 1.0 & 16 \\
\hline 11 & MF3-RF2 & 12.5 & 8.9 & 2.5 & 1.8 & 28 \\
\hline \multirow[t]{2}{*}{12} & MF3-RF3 & 12.5 & 9.1 & 3.3 & 2.5 & 25 \\
\hline & & & & 7.9 & $72 \%$ & 72 \\
\hline 13 & MF4-F & 22.7 & - & 0.5 & 0.4 & 13 \\
\hline 14 & MF4-RF1 & 8.45 & - & 1.1 & 0.6 & 25 \\
\hline 15 & MF4-RF2 & 8.2 & 8.2 & 2.2 & 1.2 & 45 \\
\hline 16 & MF4-RF3 & 8.4 & 8.0 & 3.3 & 1.5 & 38 \\
\hline \multirow[t]{2}{*}{17} & MF4-RF4 & 8.4 & 7.9 & 3.8 & 0.7 & 34 \\
\hline & & & & 10.9 & $41 \%$ & 155 \\
\hline 18 & ${ }^{*}$ MF5-F & 19.1 & - & 0.8 & 0.2 & 37 \\
\hline 19 & *MF5-RF1 & 13.6 & 12.6 & 0.8 & 0.2 & 48 \\
\hline 20 & ${ }^{*}$ MF5-RF2 & 14.4 & 11.7 & 2.6 & 0.15 & 41 \\
\hline 21 & ${ }^{*}$ MF5-RF3 & $17.7(20.5)$ & 14.7 & 4.6 & 0.2 & 49 \\
\hline \multirow[t]{2}{*}{22} & *MF5-RF4 & 15.6 & 14.1 & 0.9 & 0.2 & 3 \\
\hline & & & & 9.7 & $10 \%$ & 178 \\
\hline 23 & MF6-F & $13.5-14.7$ & 9.6 & 0.3 & 0.15 & 0 \\
\hline 24 & MF6-RF1 & 11.6 & 7.8 & 0.6 & 0.15 & 0 \\
\hline 25 & MF6-RF2 & 12.1 & 6.7 & 2.3 & 0.15 & 0 \\
\hline 26 & MF6-RF3 & 9.4 & 6.5 & 1.8 & 0.15 & 1 \\
\hline 27 & MF6-RF4 & - & 6.1 & 0.7 & 0.1 & 0 \\
\hline 28 & MF6-RF5 & - & 6.3 & 2.3 & 0.15 & 8 \\
\hline \multirow[t]{2}{*}{29} & MF6-RF6 & 10.2 & 6.7 & 1.1 & 0.15 & 5 \\
\hline & & & & 9.1 & $11 \%$ & 14 \\
\hline 30 & MF7-F & 13.5 & 5.9 & 1.0 & 0.5 & 1 \\
\hline 31 & MF7-RF1 & 5.8 & 5.7 & 1.2 & 0.5 & 1 \\
\hline 32 & MF7-RF2 & 6.0 & 5.45 & 2.2 & 1.5 & 5 \\
\hline 33 & MF7-RF3 & 6.3 & 5.3 & 3.1 & 2.5 & 1 \\
\hline \multirow[t]{2}{*}{34} & MF7-RF4 & 6.4 & 5.2 & 4.0 & 2.5 & 2 \\
\hline & & & & 11.5 & $65 \%$ & 10 \\
\hline
\end{tabular}


Table S4: Summary of injection pressure and fluid injection of the four hydraulic fracturing tests from borehole SBH1 during stress characterization phase. All hydraulic fractures were propagated in multiple refracturing cycles.

\begin{tabular}{llllll}
\hline Experiment & $\mathbf{P}_{\mathbf{c}}$ (MPa) & $\mathbf{P r}_{\mathbf{r}}(\mathbf{M P a})$ & $\mathbf{I S I P}(\mathbf{M P a})$ & $\mathbf{V}_{\mathbf{i}}(\mathbf{I})$ & $\mathbf{V}_{\mathbf{r}}(\mathbf{I})$ \\
\hline MF8 & 17.9 & 8.9 & 8.3 & 6.4 & 2.7 \\
MF9 & 19.7 & 9.8 & 9.2 & 13.8 & 1.4 \\
MF10 & 13.7 & 11 & 9.6 & 9.5 & 0.8 \\
MF11 & 19.1 & 9.65 & 9.2 & 8.8 & 5.2 \\
\hline
\end{tabular}

\section{S5: Fracture orientation determination from borehole logging and seismic plane analyses}

Table S5 summarize the trace description from the acoustic televiewer for the HF experiments inclusive sinusoidal trace fit with the software wellcad (advance logic technology) resulting in true dip direction and $\operatorname{dip}\left(x x x / x x^{\circ}\right)$ at the specific depth. The optical teleview borehole logging was done for the fracture traces in $\mathrm{SBH} 3$ and impression packer were used for the tests executed in SBH1.

For each HF experiment, we tried to fit a plane through the seismic cluster using an orthogonal distance regression criterion. The same approach was used for the minifracs by Gischig et al. (2018). The planes considering all located seismic events for test HF8 show a comparable orientation with the MF planes. The misfit of the plane for the test HF8 is $0.52 \mathrm{~m}$. Test HF2 show two clusters with different oriented planes. The first cluster is located next to the injection borehole and occurs mainly through injection cycle RF1 and the second one is located further towards E during cycle RF2. One plane is oriented towards NNE with a dip of $83^{\circ}$ and the misfit is $0.26 \mathrm{~m}$ and the other plane is oriented towards $S$ with a dip of $76^{\circ}$ (misfit: $0.34 \mathrm{~m}$ ). Two clusters are observed for HF3 with one cluster aligned towards $E$ with a dip of $42^{\circ}$ and a second one towards $S$ with a dip of $62^{\circ}$. The misfit is 1.17 respective $1.47 \mathrm{~m}$. The cluster with the smaller misfit includes all seismic events occurring between frac cycle and to the end of the refrac cycle RF2 (inclusive bleed-off). The seismic events occurring between the end of RF2 and the end of the experiment show a big misfit, with many events occurring during the shut-in phase. The dip and dip direction of HF3 become more comparable with test HF2 and HF8. This was done due to the fact that two different fracture systems associated with the zone $\mathrm{S} 3$ show the same orientation than the two plane fits from test HF3. Both fracture systems together are able to effectively drain the fracture fluid towards the AU tunnel. The few seismic events occurring during HF5, show similar orientation for the ATV trace and the seismic cluster with a small misfit of $0.18 \mathrm{~m}$.

Table S5: Trace description form geophysical borehole logging incl. trace fit and plane fit through located micro-seismic events. HF1-HF8 trace fit from ATV geophysical borehole logging; MF1-MF3 and MF8-MF11 trace fit from optical teleview logging and impression packer (Klee, 2015) and seismic plane fit (Gischig et al., 2018; Näf, 2017).

a,btwo clusters were observed

\begin{tabular}{|c|c|c|c|c|}
\hline Experiment & Borehole & Trace description & $\begin{array}{l}\text { Trace fit } \\
\mathbf{x x x} / \mathbf{x x}^{\circ}\end{array}$ & $\begin{array}{l}\text { Plane fit } \\
\mathbf{x x x} / \mathbf{x x}^{\circ}\end{array}$ \\
\hline HF1 & INJ1 & $\begin{array}{l}\text { axial trace hits pre-existing } \\
\text { fracture; } \\
39.5-41.0 \mathrm{~m}\end{array}$ & $359 / 71^{\circ} @ 40.55 \mathrm{~m}$ & $N / A$ \\
\hline HF2 & INJ1 & $\begin{array}{l}\text { steeply inclined incomplete axial } \\
\text { trace; } \\
35.8-37.1 \mathrm{~m}\end{array}$ & $\begin{array}{l}049 / 89^{\circ} @ 35.44 \mathrm{~m} \\
022 / 69^{\circ} @ 36.21 \mathrm{~m}\end{array}$ & $\begin{array}{l}029 / 83^{\circ \mathrm{a}} \\
175 / 46^{\circ \mathrm{a}}\end{array}$ \\
\hline HF3 & INJ1 & $\begin{array}{l}\text { steeply inclined axial trace; } \\
20.1-21.2 \mathrm{~m}\end{array}$ & $\begin{array}{l}205 / 88^{\circ} @ 20.72 \mathrm{~m} \\
031 / 82^{\circ} @ 21.08 \mathrm{~m}\end{array}$ & $\begin{array}{l}067 / 46^{\circ b} \\
156 / 49^{\circ b}\end{array}$ \\
\hline HF5 & INJ1 & axial single trace; $13.8-15.6 \mathrm{~m}$ & $029 / 79^{\circ} @ 14.8 \mathrm{~m}$ & $013 / 75^{\circ}$ \\
\hline HF6 & INJ2 & $\begin{array}{l}2 \text { pre-existing axial traces between } \\
\text { two fractures; } 39.2-39.9 \mathrm{~m}\end{array}$ & $\left(021 / 59^{\circ} @ 39.71 \mathrm{~m}\right)$ & - \\
\hline
\end{tabular}




\begin{tabular}{lllll}
\hline HF8 & INJ2 & steeply inclined axial trace; $15.8-$ & $027 / 74^{\circ} @ 16.01 \mathrm{~m}$ & $179 / 69^{\circ}$ \\
MF1 & SBH3 & steeply inclined fracture & $139 / 71^{\circ}$ & $180 / 72^{\circ}$ \\
MF2 & SBH3 & inclined fracture & $142.5 / 71.3^{\circ}$ & $175 / 76^{\circ}$ \\
MF3 & SBH3 & No fracture detected & - & $178 / 69^{\circ}$ \\
MF4 & SBH4 & - & - & $185 / 73^{\circ}$ \\
MF5 & SBH4 & - & - & $001 / 65^{\circ}$ \\
MF6 & SBH4 & - & - & $162 / 64^{\circ}$ \\
MF7 & SBH4 & - & - & $185 / 73^{\circ}$ \\
MF8 & SBH1 & steeply inclined fracture & $155 / 83^{\circ}$ & - \\
MF9 & SBH1 & sub-horizontal & $161 / 81^{\circ}$ & - \\
MF10 & SBH1 & axial single trace & $200 / 82^{\circ}$ & - \\
MF11 & SBH1 & steeply inclined fracture & $173 / 79^{\circ}$ & - \\
\hline
\end{tabular}

\section{S6: Experimental summary cards}

Figure $\mathrm{S} 6$ presents an overview of the injection interval locations for the HF tests and the minifracs (MF) from the stress characterization phase. The following figures present each test and summarize in short, the injection protocol inclusive flow rate and injection pressure, the seismic location in map and profile view over different frac/refrac cycles. In addition, the radial distance from the injection point (inclusive amplitude magnitude for the minifracs) and fluid injection and fluid backflow volume are presented.
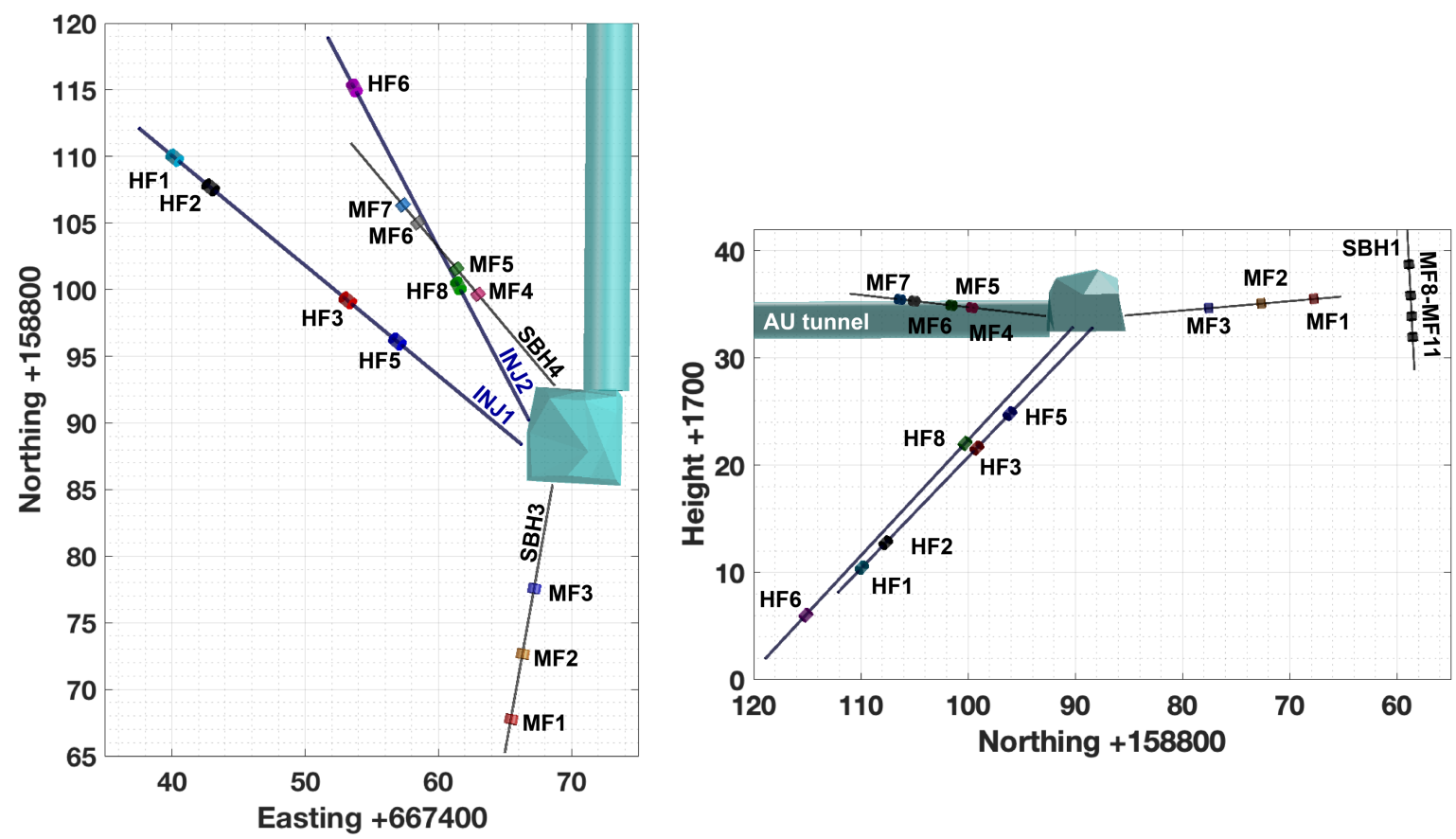

Figure S6: Overview of the injection interval locations for the experimental summary cards presented hereinafter. 
HF1

HF1a, 15.05.2017

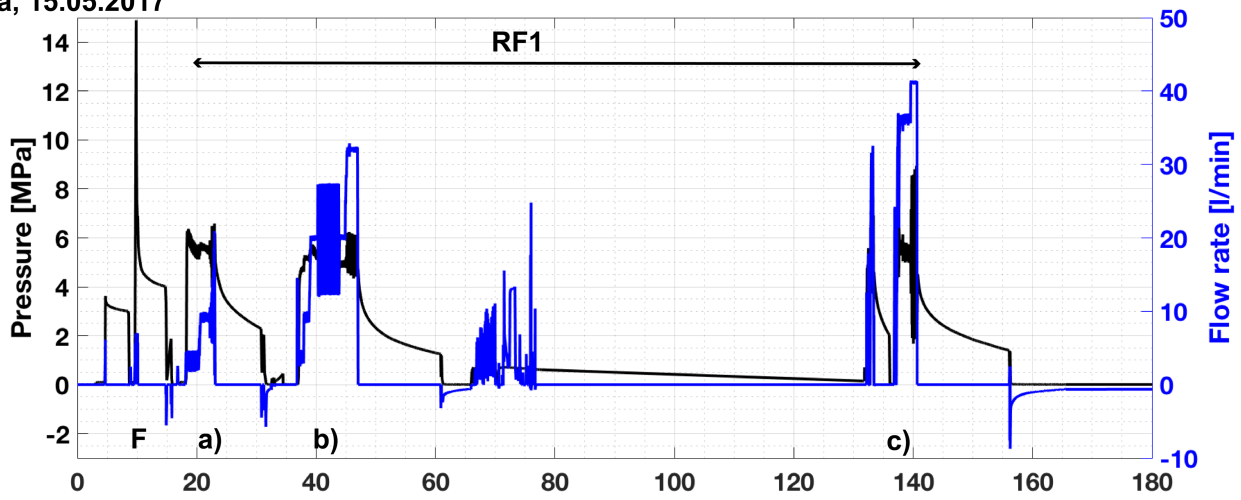

HF1b, 16.05 .2017

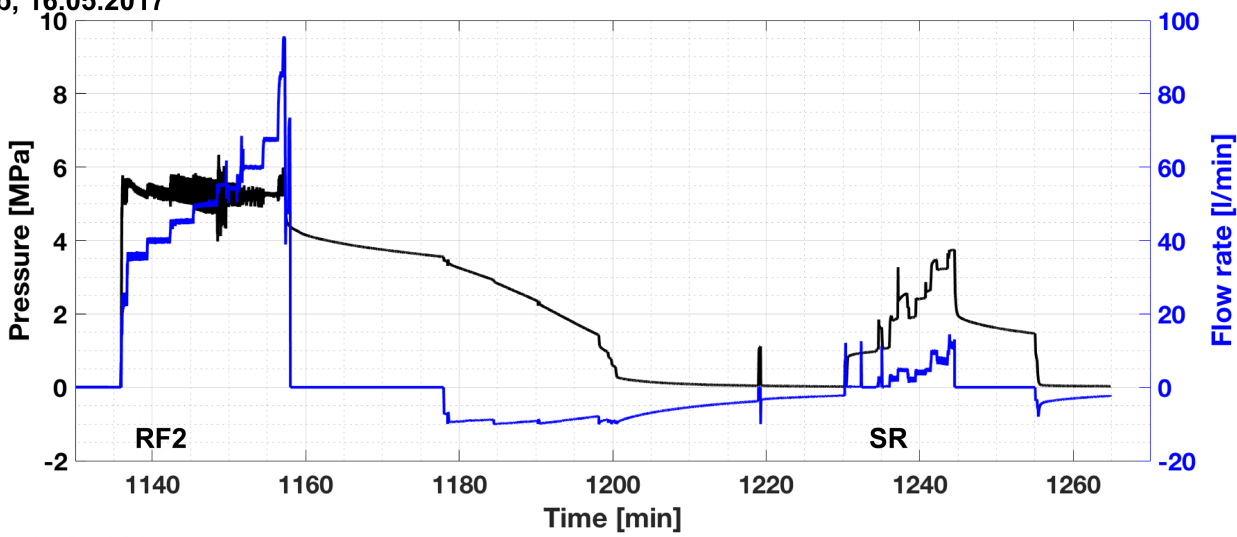

HF1a, 15.05.2017

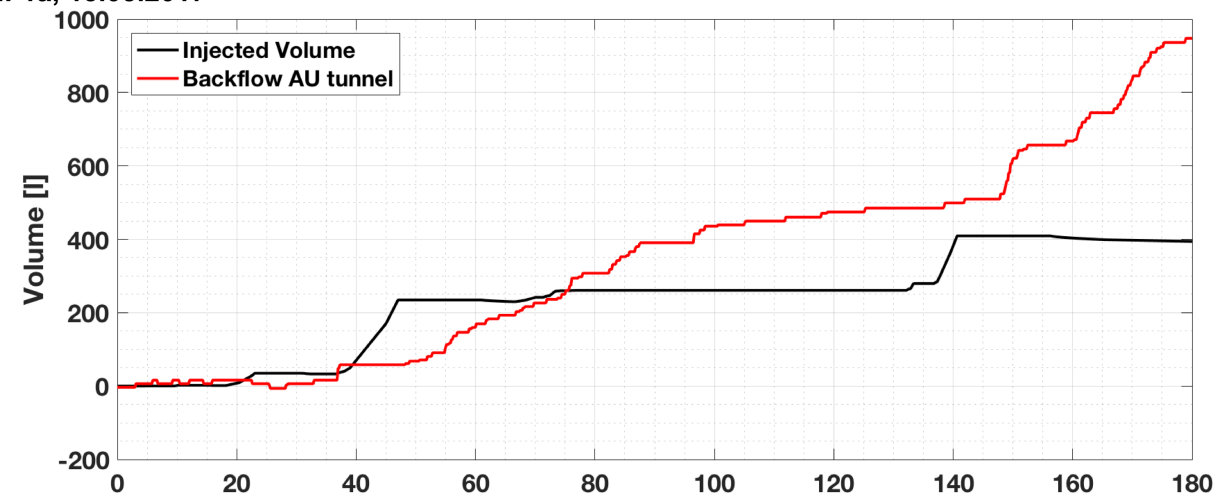

HF1b, 16.05.2017

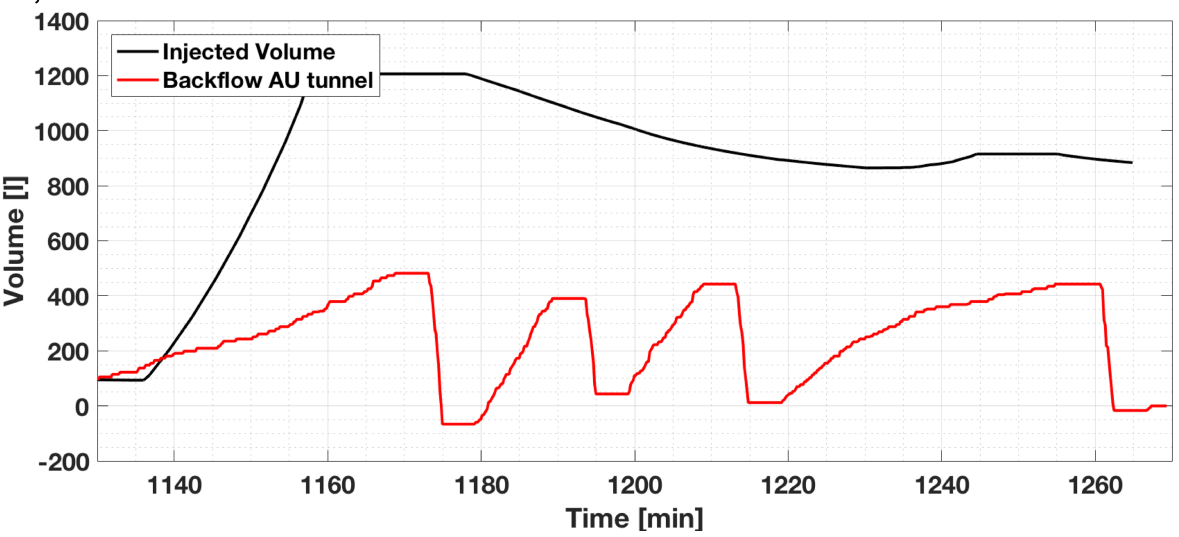

Figure S7: Injection pressure [MPa] and flow rate [l/min] for HF1a executed at the 15.05.2017 and HF1b at the 16.05.2017. The test HF1a was stopped due to water supply problems. The new supply pump arrived the day later and was able to give flow rates of up to $90 \mathrm{l} / \mathrm{min}$. The injected volume corresponds to the trapezoidal integration of the flow rate incl. negative flow. The backflow from the AU tunnel is indirect measured by pressure sensor and should not be used for this test as additional water was added to the AU tunnel testing the pump and installing Gas-Equilibrium Membrane Inlet Mass Spectrometry on the seepage zone of the S3 shear zone in the AU tunnel. 
HF3

a)
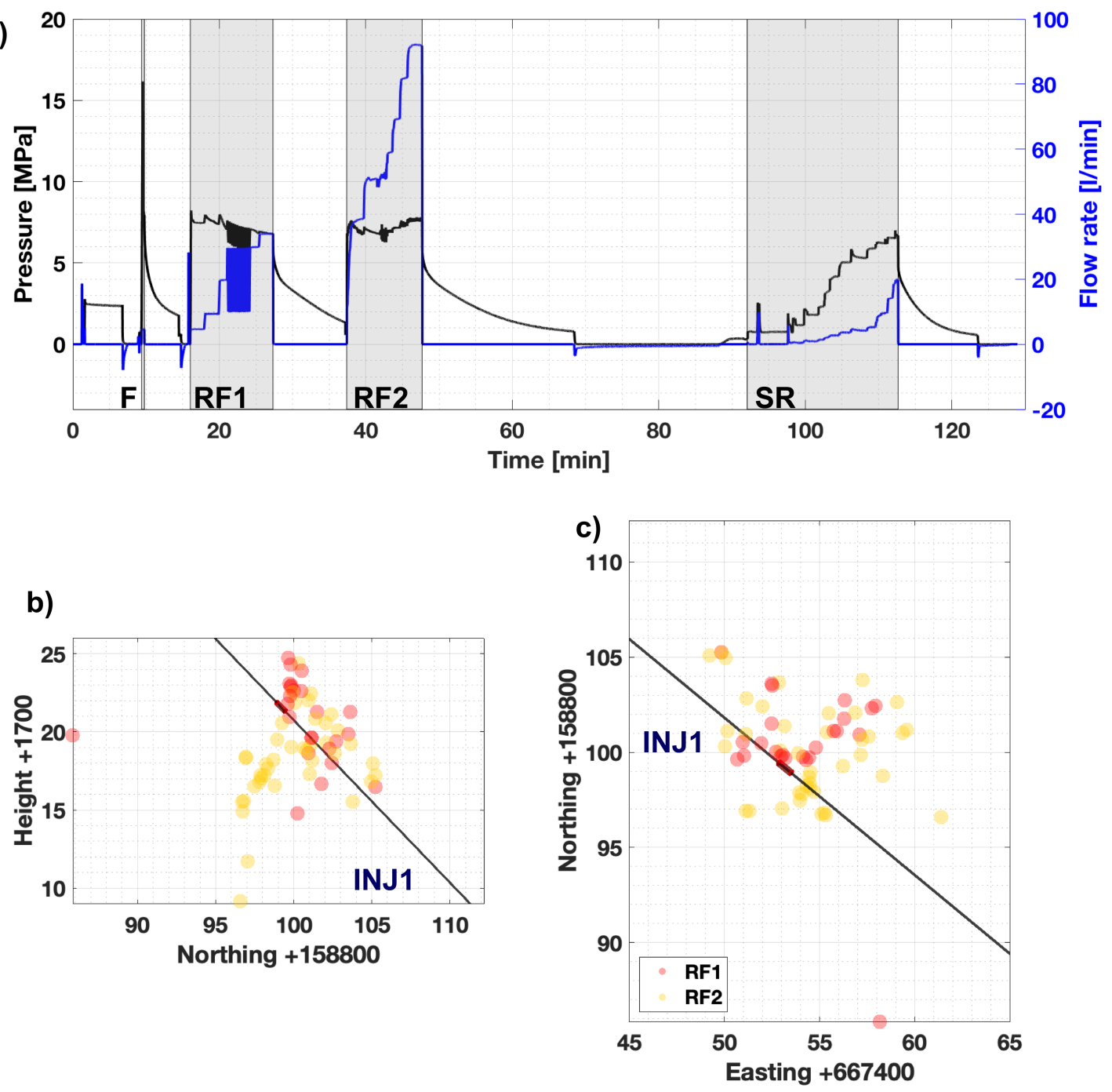

b)
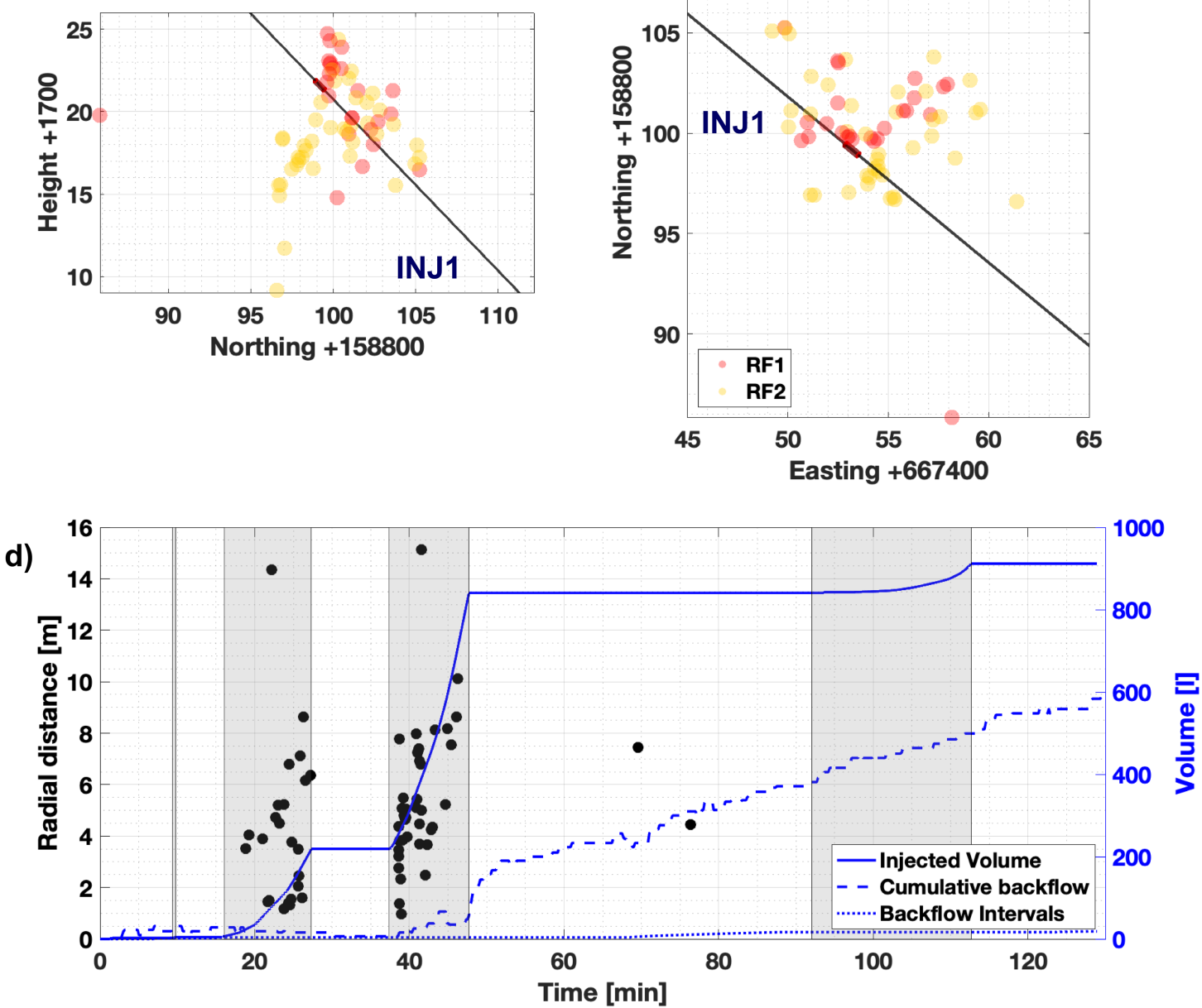

Figure S8: a) Injection pressure [MPa] and flow rate [l/min] are indicated for HF3 with gray shaded boxes during fluid injection. The overview of the located seismic events is presented in plane (b) and profile view (c). The red cylinder corresponds to the injection interval and the located seismic events are differently colored depending on the injection stage. d) The radial distance from the injection interval to the seismic event is presented and the magnitude is indicated by color code. The cumulative injection volume and the cumulative backflow are presented by blue solid respective dashed line. All seismic events taking place during fluid injection. 
HF2

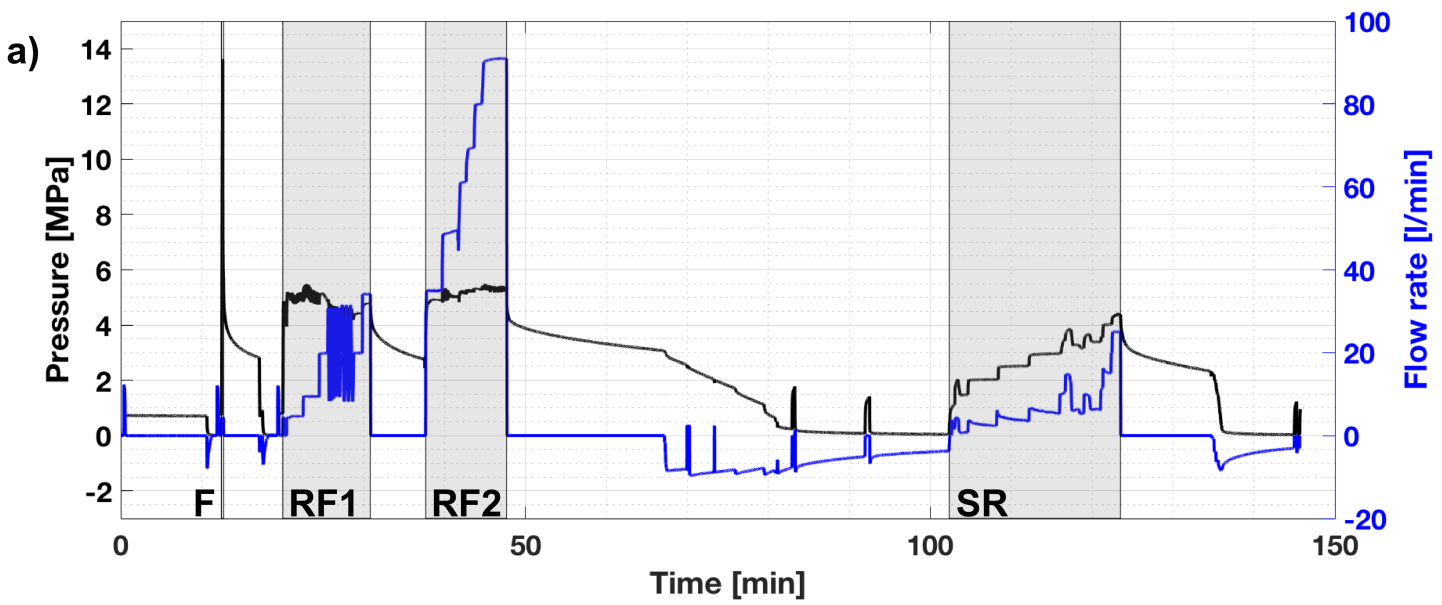

b)
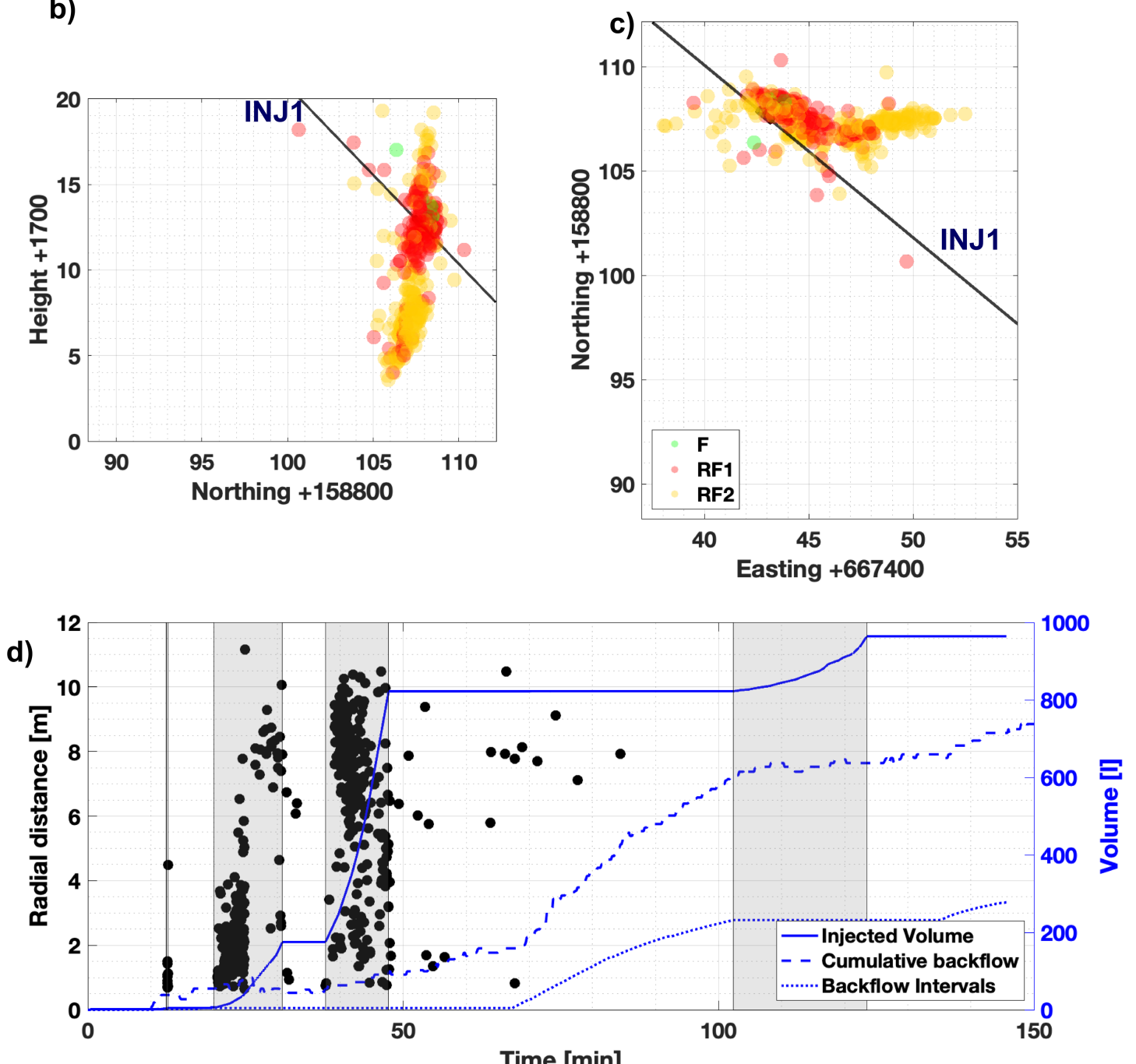

Figure S9: a) Injection pressure [MPa] and flow rate [l/min] are indicated for HF2 with gray shaded boxes during fluid injection. The overview of the located seismic events is presented in plane (b) and profile view (c). The red cylinder corresponds to the injection interval and the located seismic events are differently colored depending on the injection stage. d) The radial distance from the injection interval to the seismic event is presented and the magnitude is indicated by color code. The cumulative injection volume and the cumulative backflow are presented by blue solid respective dashed line. Most seismic events taking place during fluid injection. 


\section{HF5}

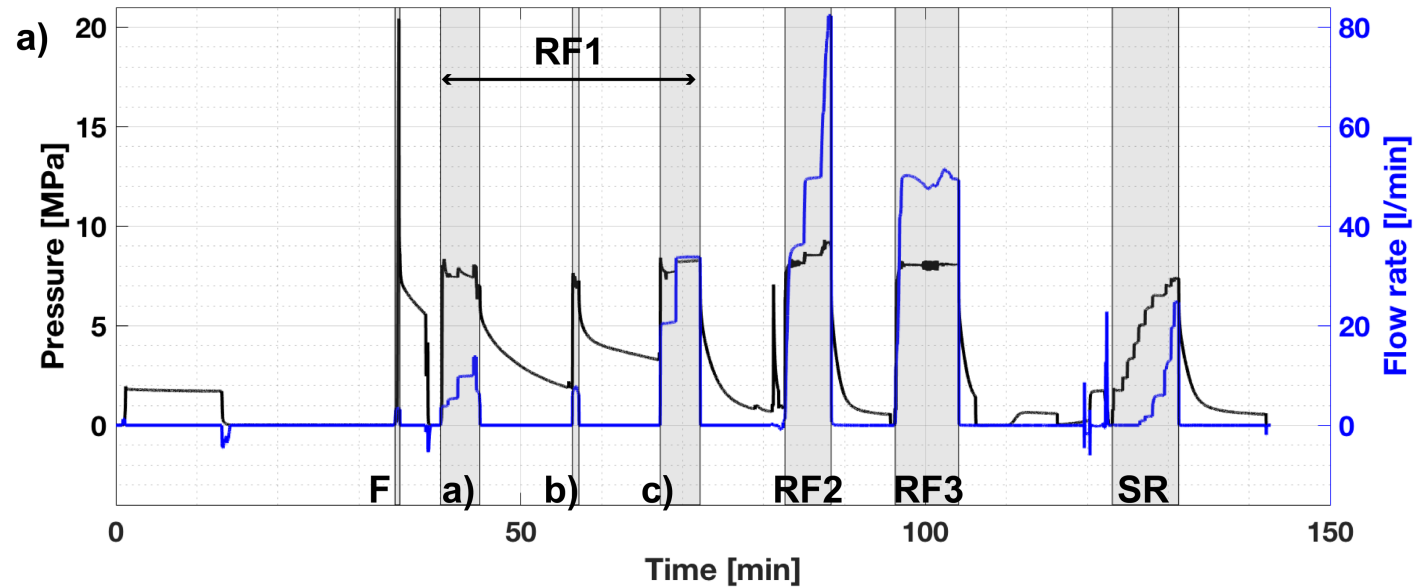

c)

b)
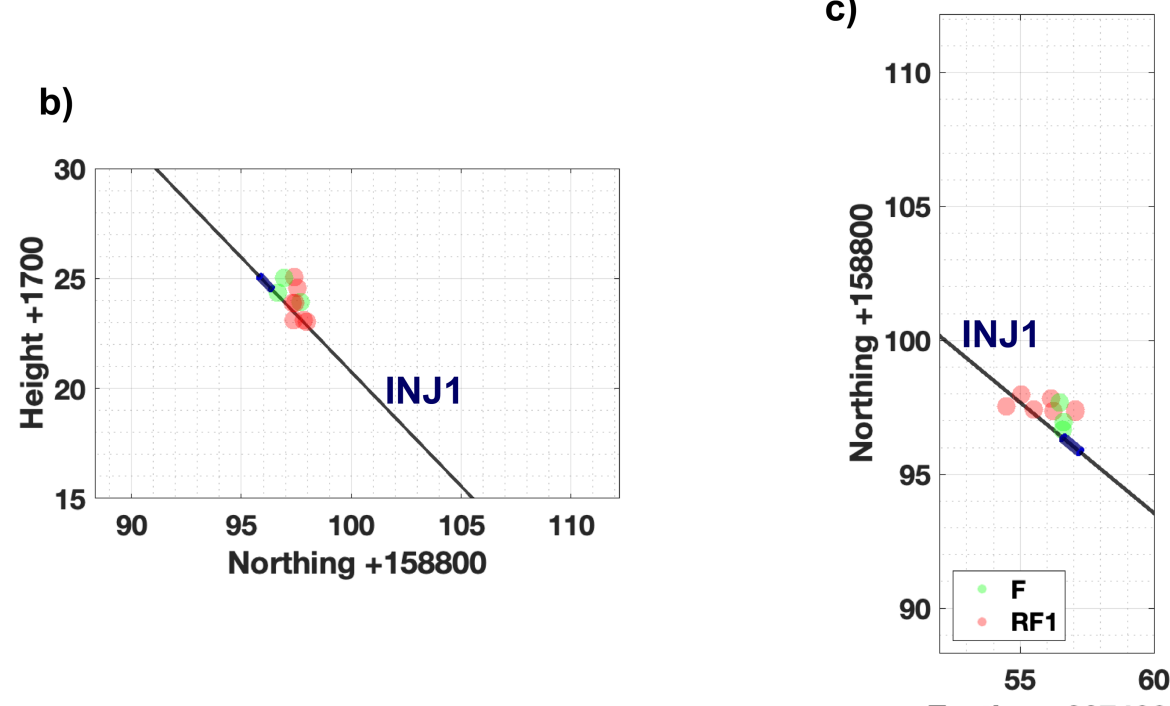

Easting +667400

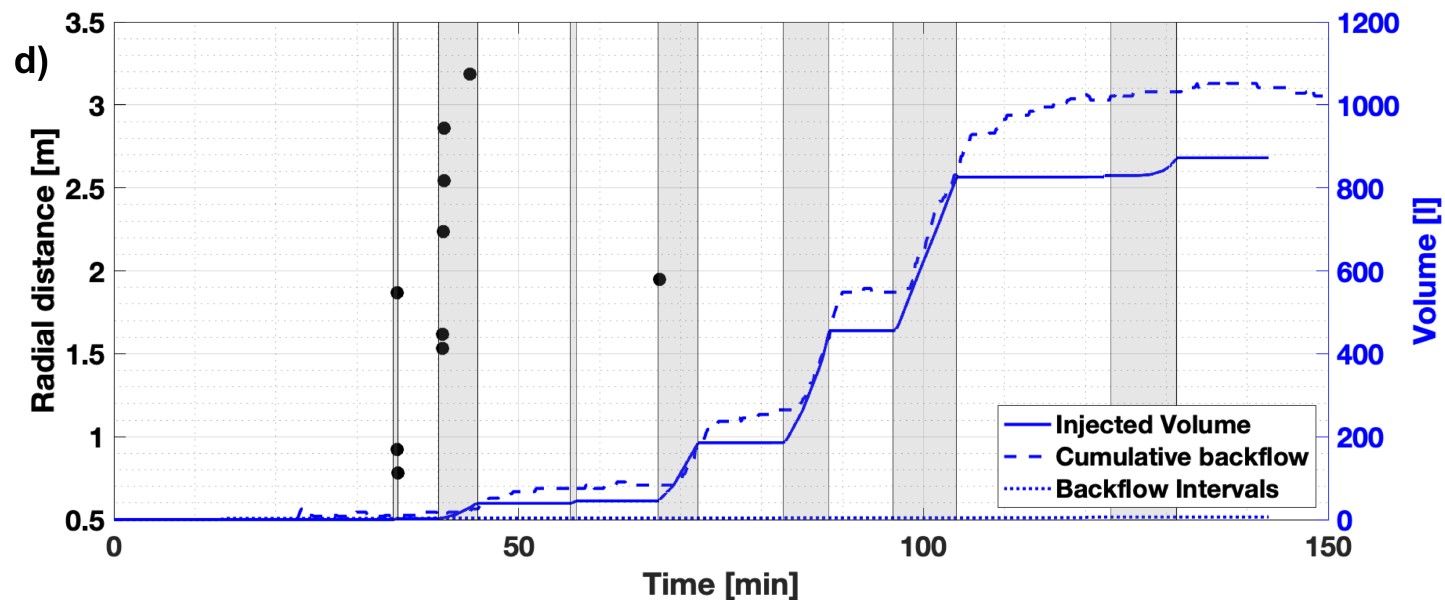

Figure S10: a) Injection pressure [MPa] and flow rate [1/min] are indicated for HF5 with gray shaded boxes during fluid injection. The protocol differs due to a short-cut to one of the geophysical boreholes. The overview of the located seismic events is presented in plane (b) and 3D view (c). The red cylinder corresponds to the injection interval and the located seismic events are differently colored depending on the injection stage. d) The radial distance from the injection interval to the seismic event is presented and the magnitude is indicated by color code. The cumulative injection volume and the cumulative backflow are presented by blue solid respective dashed line. Only a few seismic events were located during this experiment. As one of the geophysical boreholes was hit during the first propagation cycle, the outflow through the borehole increased the noise at the seismic sensors placed in the borehole. 
HF6
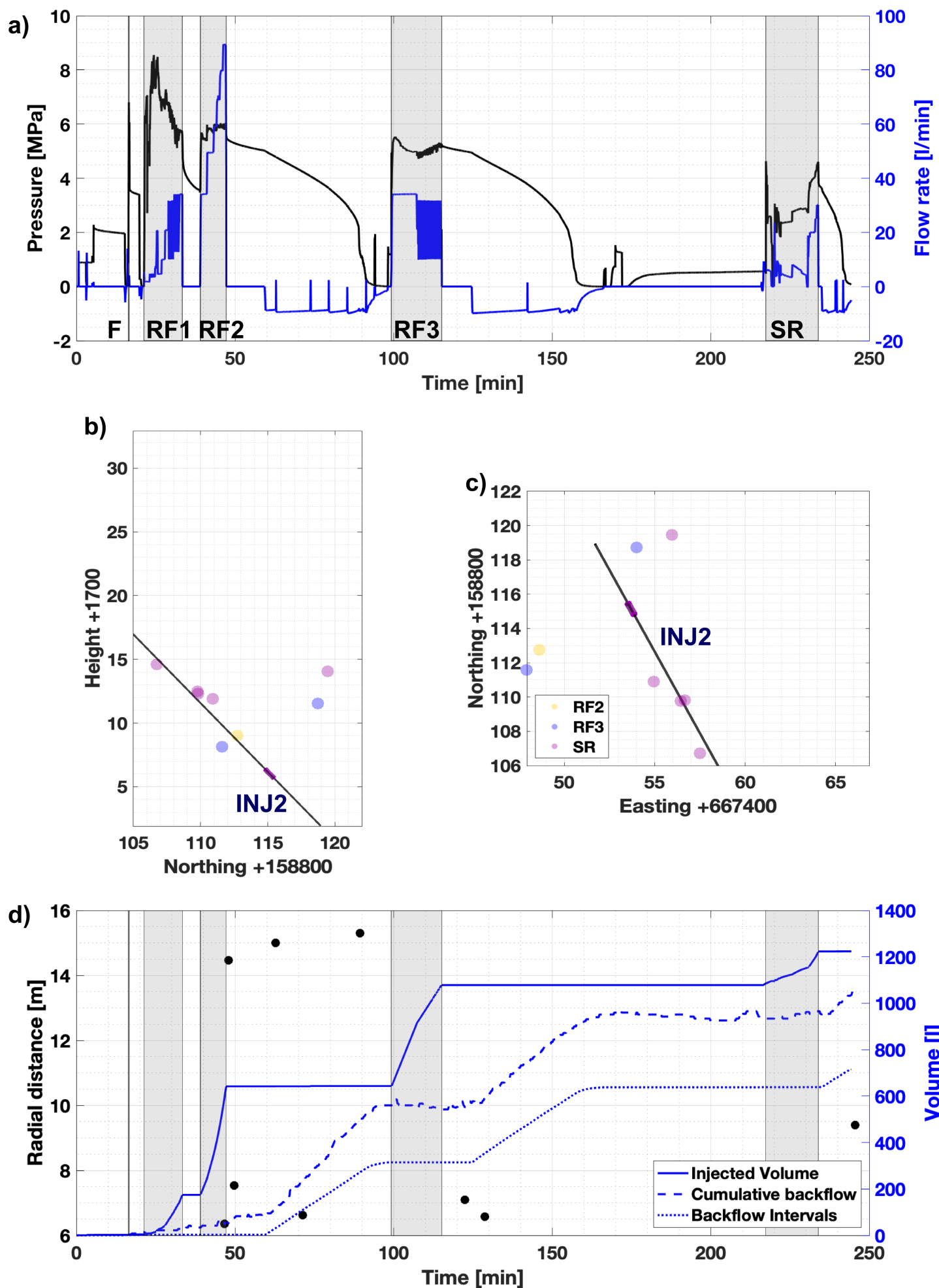

Figure S11: a) Injection pressure [MPa] and flow rate [l/min] are indicated for HF6 with gray shaded boxes during fluid injection. This experiment was mistakenly stimulated at the wrong position with a pre-existing fracture, which directly is correlated with a small break down pressure. The overview of the located seismic events is presented in plane (b) and profile view (c). The red cylinder corresponds to the injection interval and the located seismic events are differently colored depending on the injection stage. Most of the seismic takes place along the PRP2 borehole. d) The radial distance from the injection interval to the seismic event is presented and the magnitude is indicated by color code. The cumulative injection volume and the cumulative backflow are presented by blue solid respective dashed line. Only a few seismic events were located during this experiment. During this experiment larger magnitudes are observed. In addition, most of seismic took place during shut-in and bleed-off. 


\section{HF8}

a)

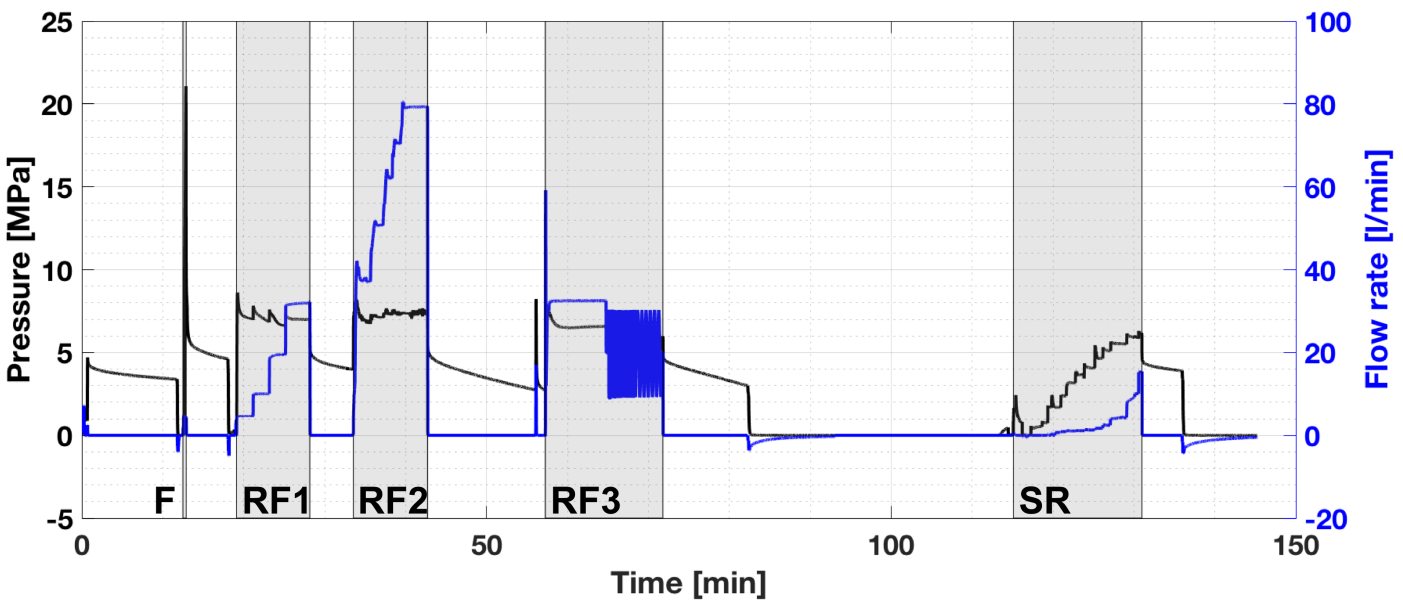

b)
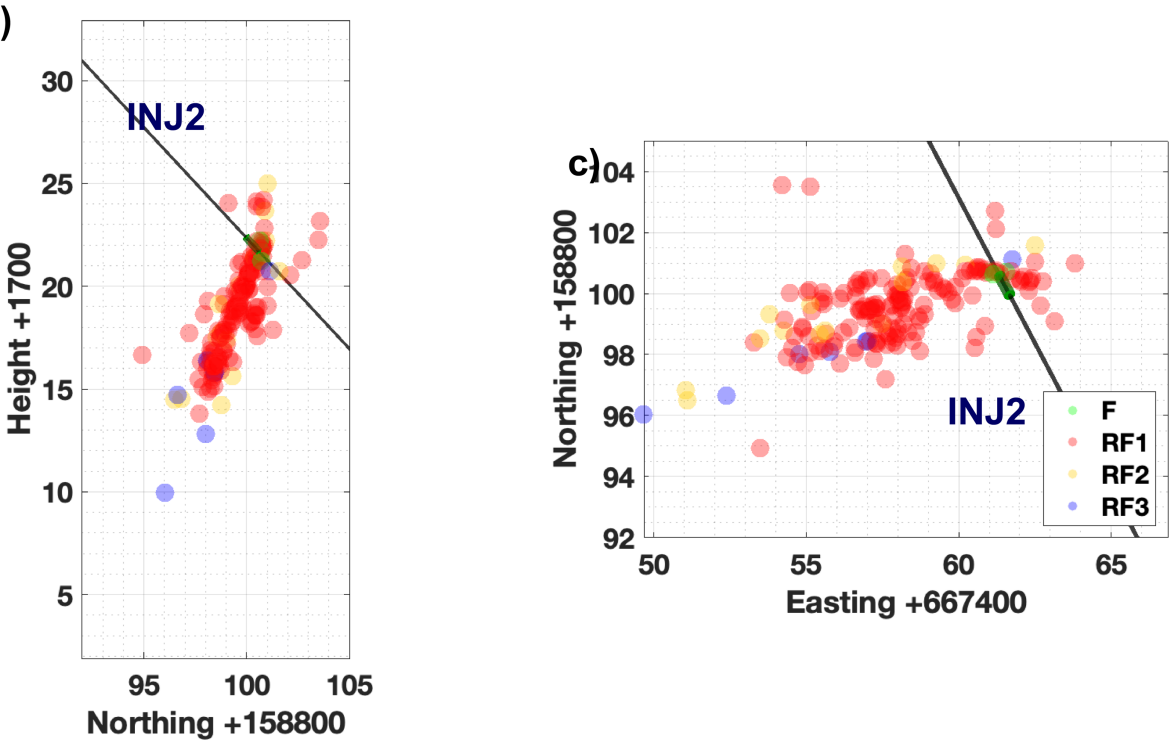

Northing +158800

d)

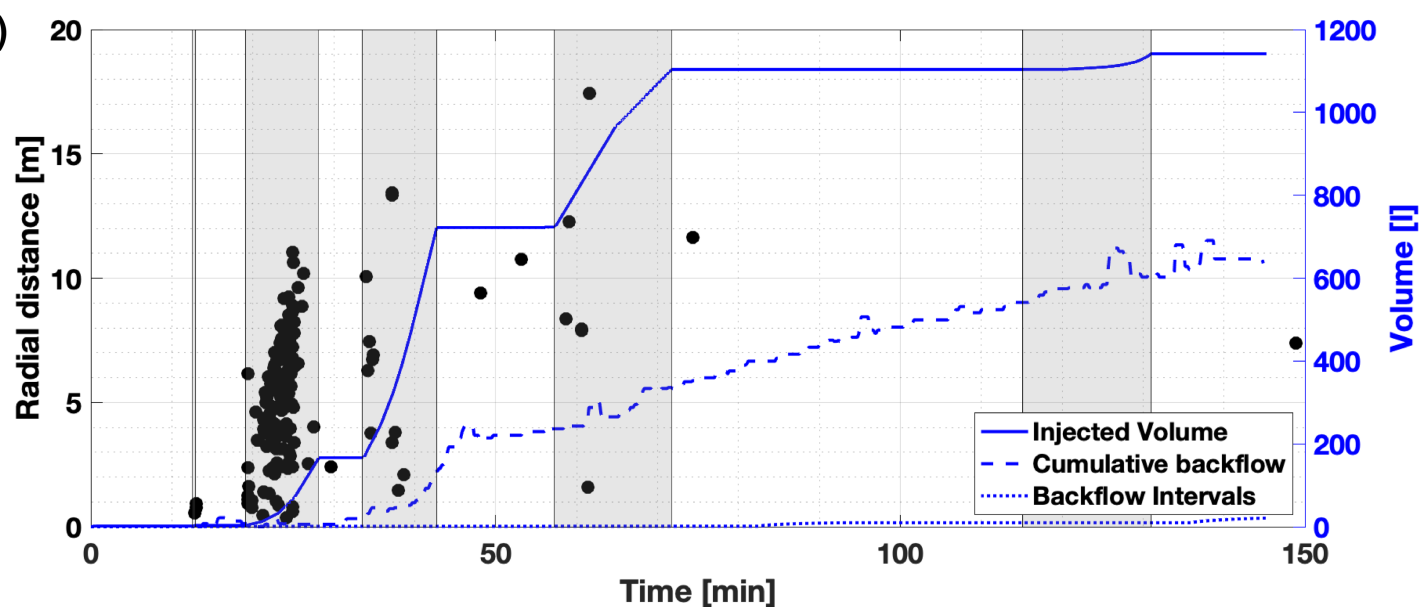

Figure S12: a) Injection pressure [MPa] and flow rate $[\mathrm{l} / \mathrm{min}]$ are indicated for HF8 with gray shaded boxes during fluid injection. The overview of the located seismic events is presented in plane (b) and profile view (c The red cylinder corresponds to the injection interval and the located seismic events are differently colored depending on the injection stage. d) The radial distance from the injection interval to the seismic event is presented and the magnitude is indicated by color code. The cumulative injection volume and the cumulative backflow are presented by blue solid respective dashed line. Most of the seismic took place during the first fracture propagation cycle. 
MF1

a)

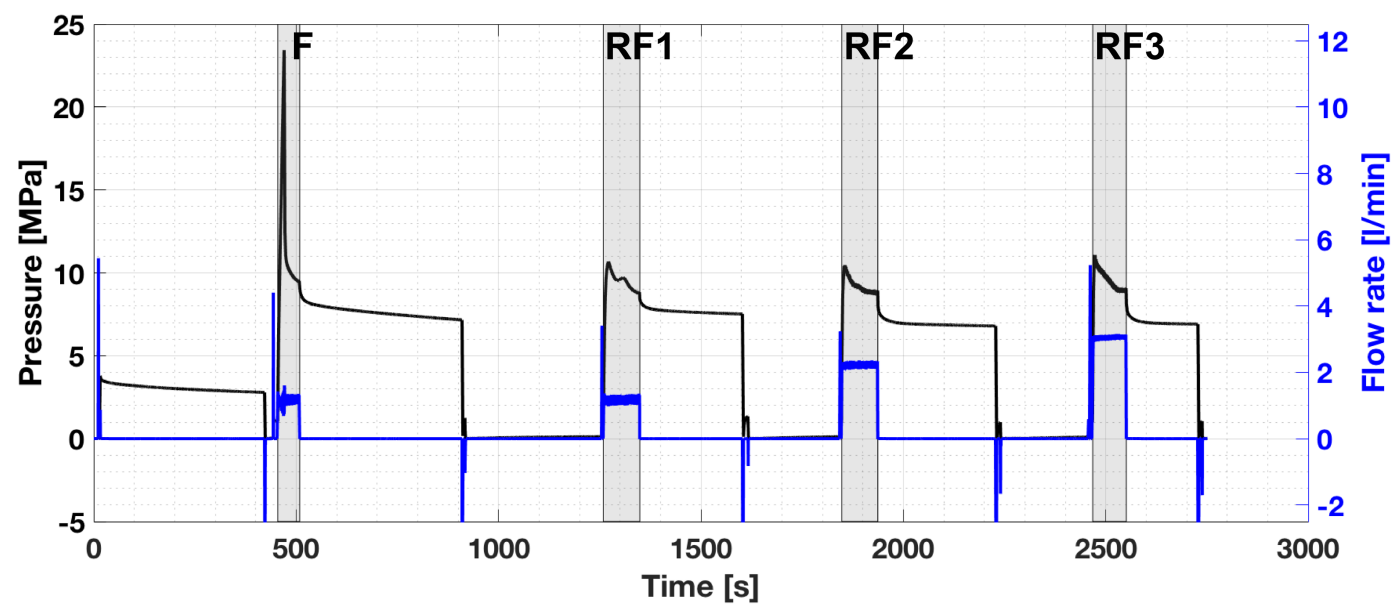

b)

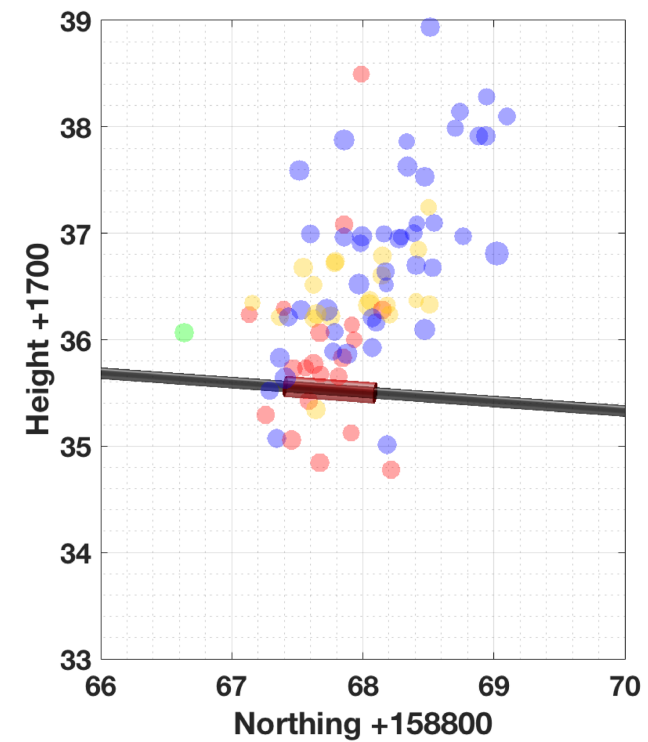

c)

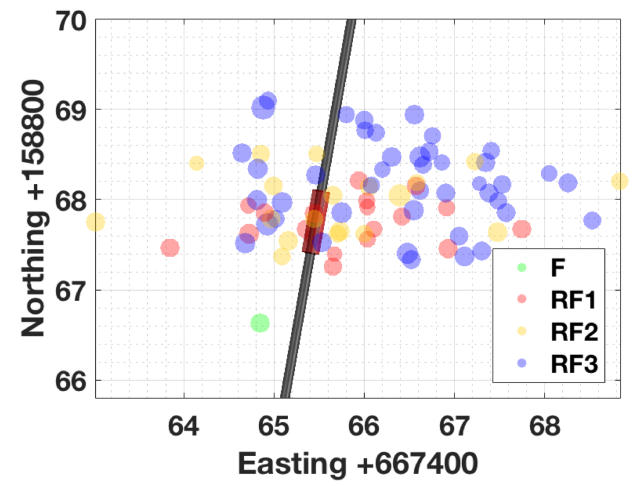

d)

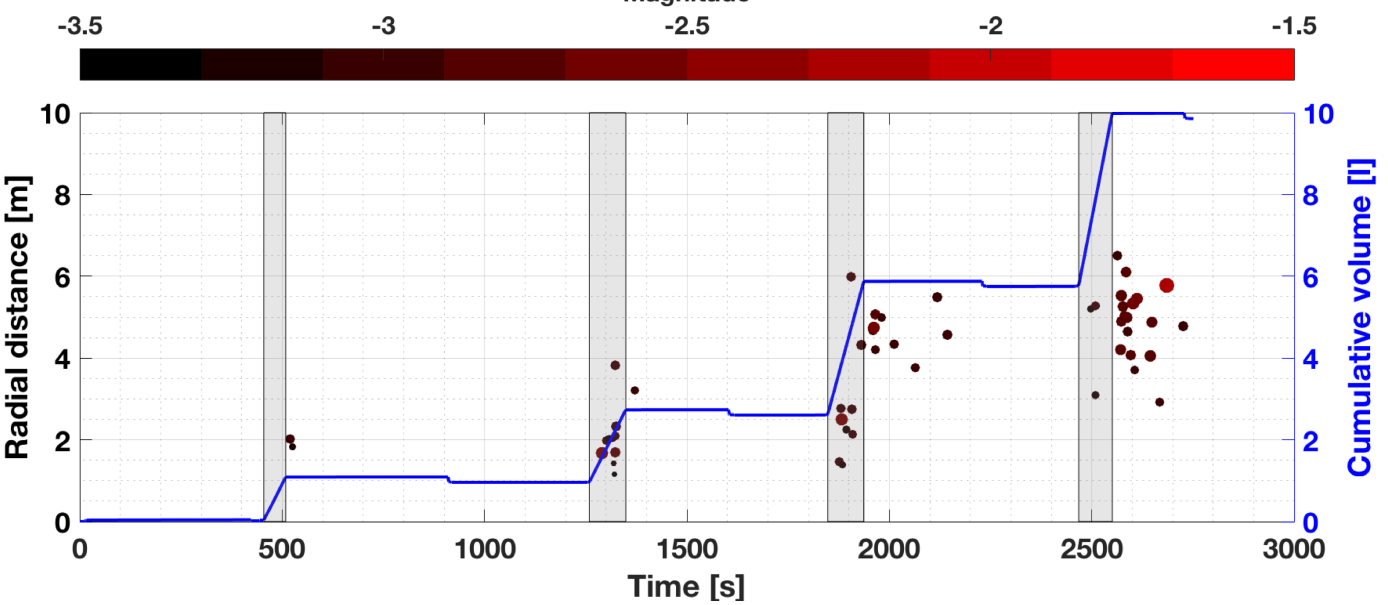

Figure S13: a) Injection pressure [MPa] and flow rate [1/min] are indicated for MF1 with gray shaded boxes during fluid injection. The overview of the located seismic events is presented in plane (b) and profile view (c). $d$ ) The radial distance from the injection interval to the seismic event is presented and the magnitude is indicated by color code. The cumulative injection volume is presented by blue solid line. 
MF2
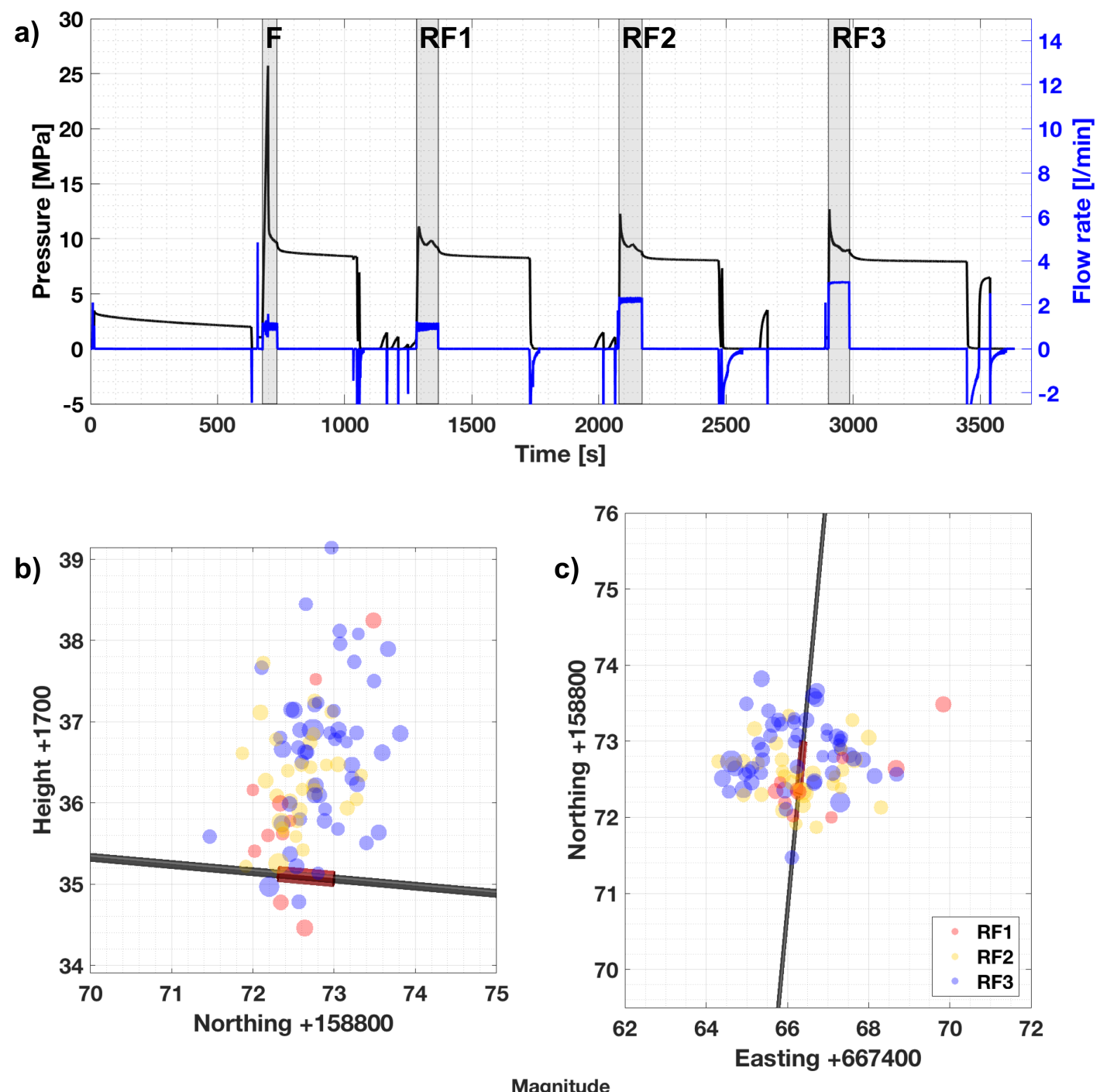

d)
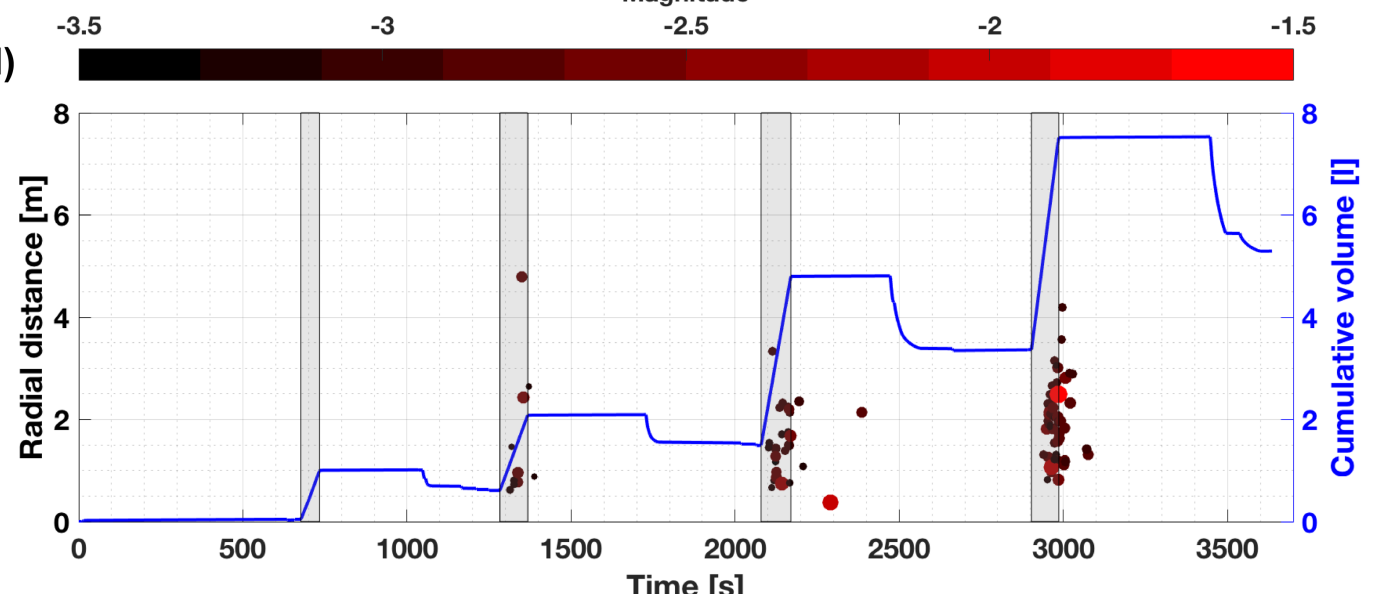

Figure S14: a) Injection pressure [MPa] and flow rate [l/min] are indicated for MF2 with gray shaded boxes during fluid injection. The overview of the located seismic events is presented in plane (b) and profile view (c). $d$ ) The radial distance from the injection interval to the seismic event is presented and the magnitude is indicated by color code. The cumulative injection volume is presented by blue solid line. 
MF3

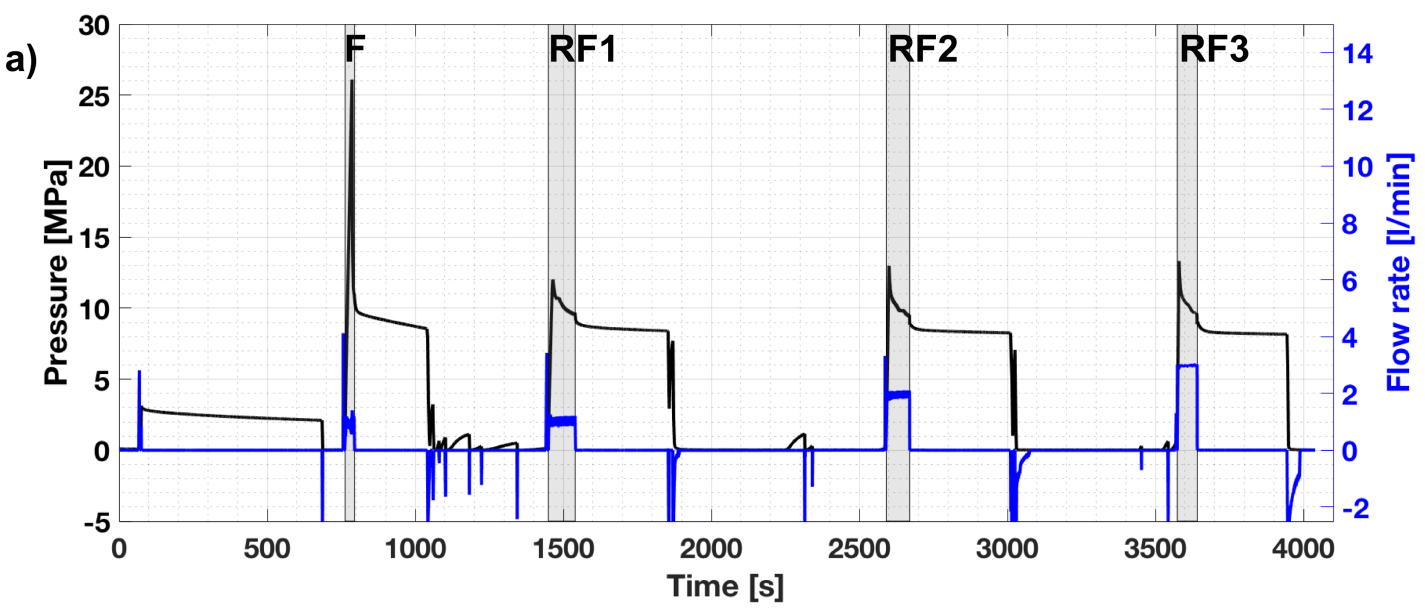

b)

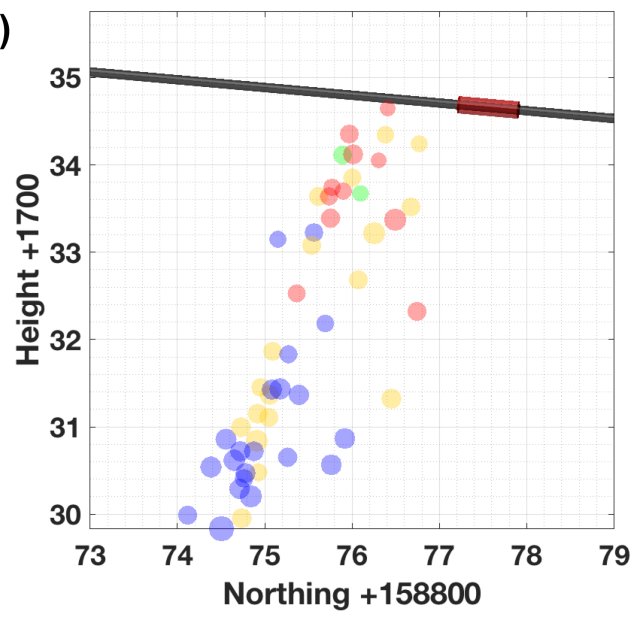

c)

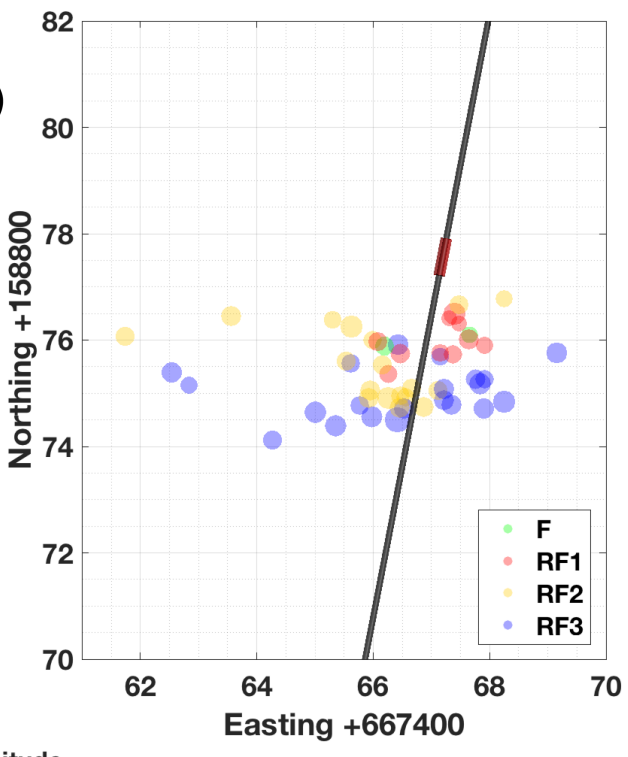

d)
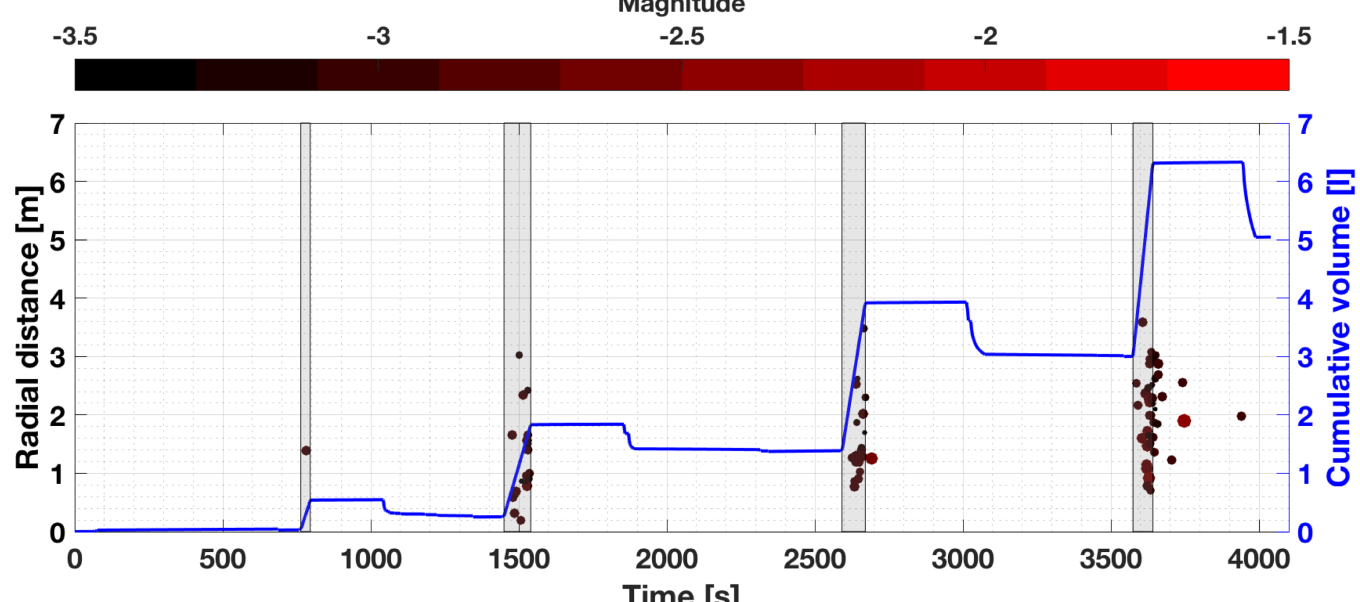

Figure S15: a) Injection pressure [MPa] and flow rate [l/min] are indicated for MF3 with gray shaded boxes during fluid injection. The overview of the located seismic events is presented in plane (b) and profile view (c). d) The radial distance from the injection interval to the seismic event is presented and the magnitude is indicated by color code. The cumulative injection volume is presented by blue solid line. 
MF4
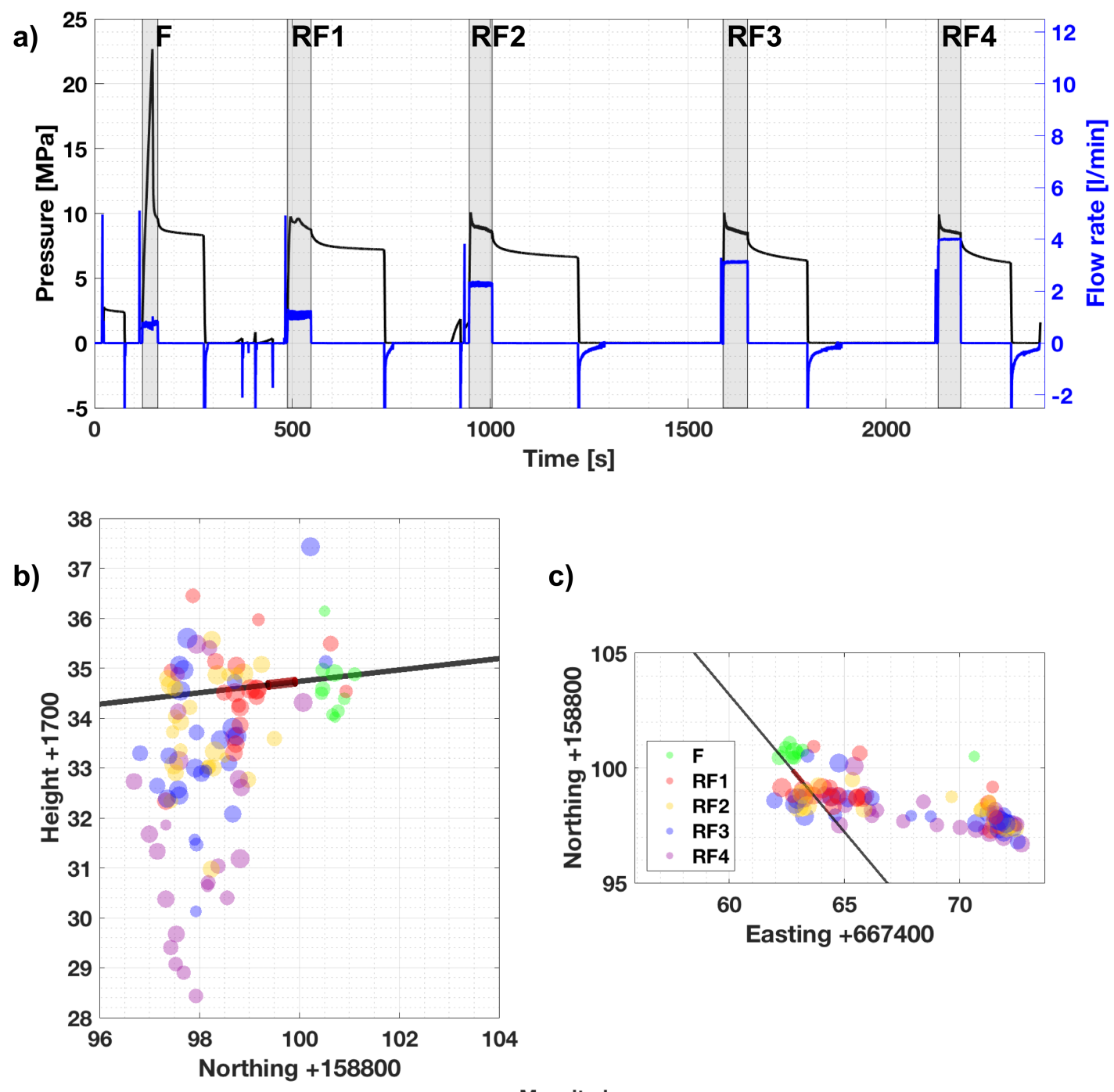

c)

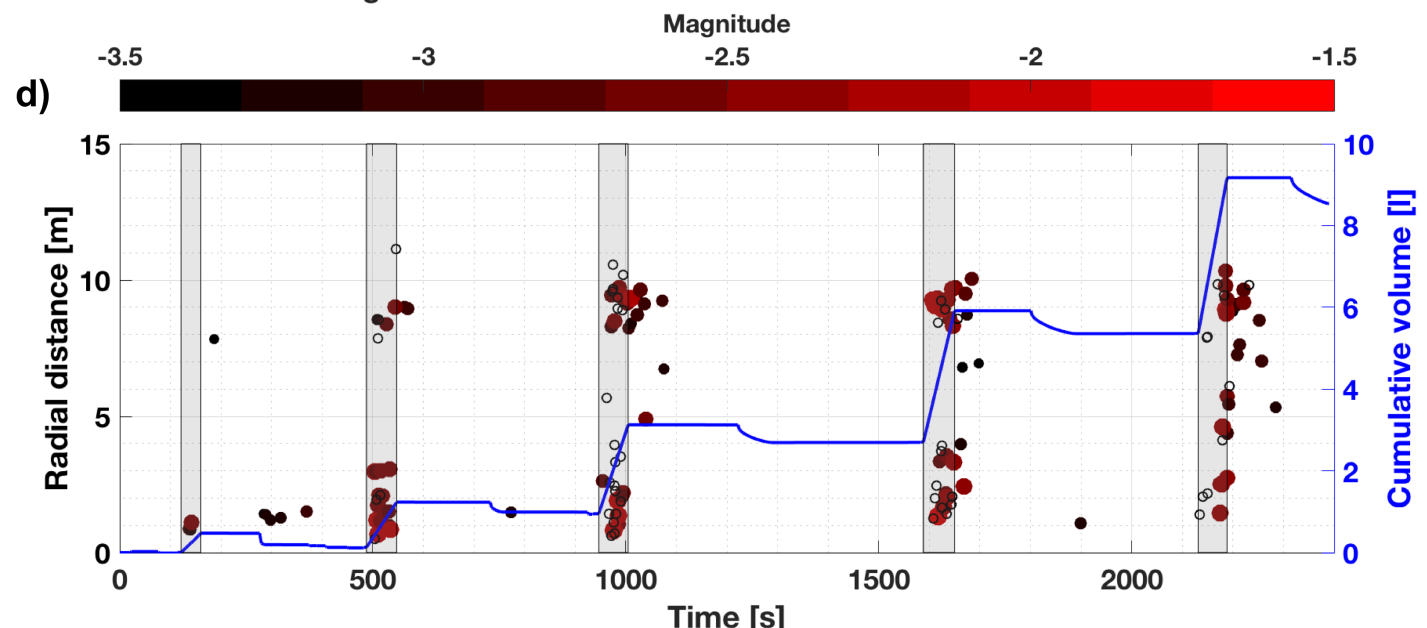

Figure S16: a) Injection pressure [MPa] and flow rate [l/min] are indicated for MF4 with gray shaded boxes during fluid injection. The overview of the located seismic events is presented in plane (b) and profile view (c). d) The radial distance from the injection interval to the seismic event is presented and the magnitude is indicated by color code. The cumulative injection volume is presented by blue solid line. 


\section{MF5}

a)

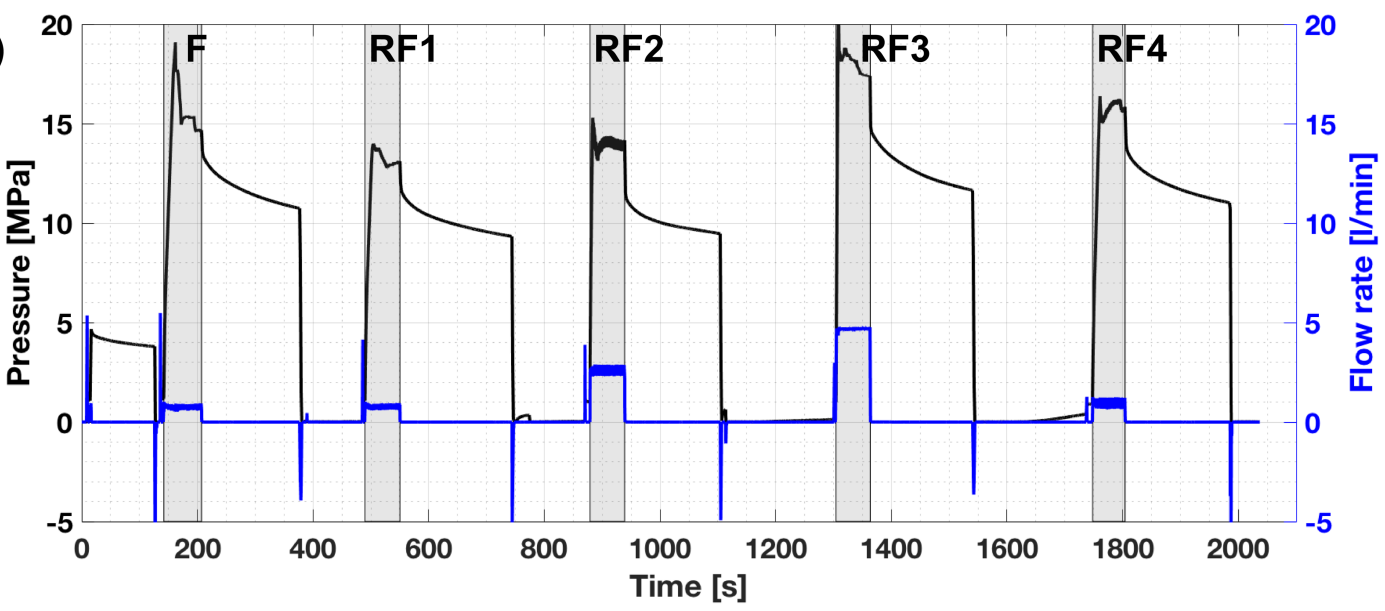

b)

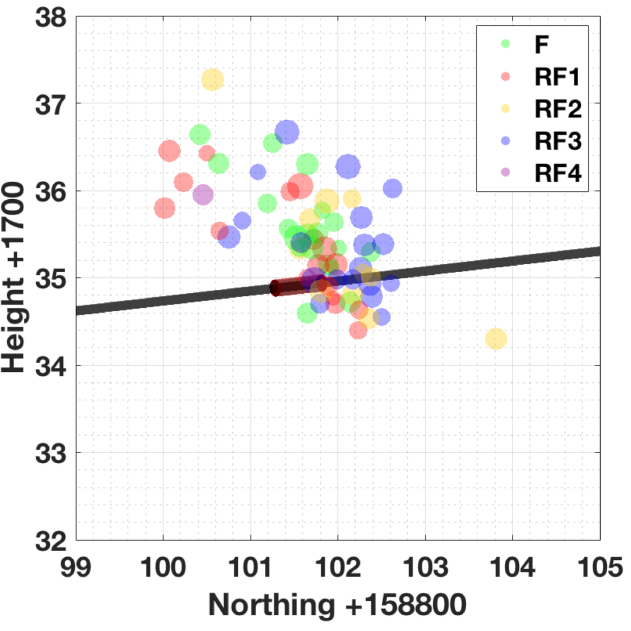

c)

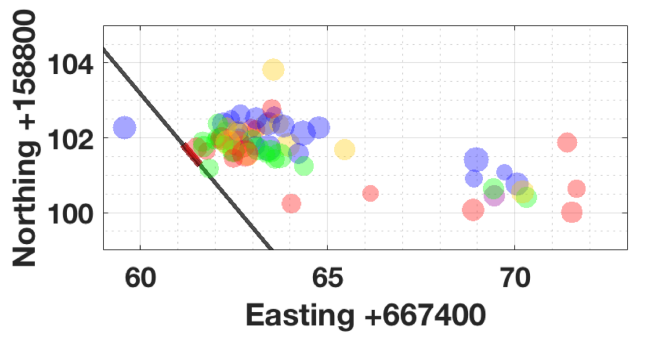

Magnitude

$-2.5$

d)

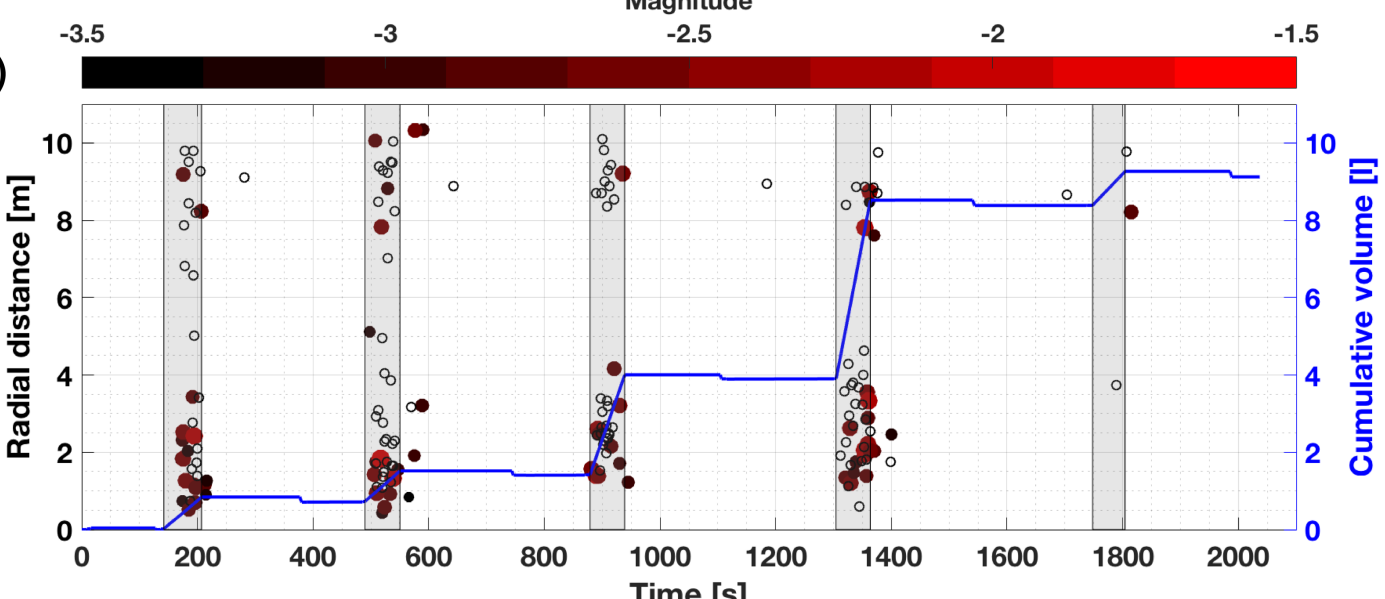

Figure S17: a) Injection pressure [MPa] and flow rate [1/min] are indicated for MF5 with gray shaded boxes during fluid injection. The overview of the located seismic events is presented in plane (b) and profile view (c). d) The radial distance from the injection interval to the seismic event is presented and the magnitude is indicated by color code. The cumulative injection volume is presented by blue solid line. 
MF6
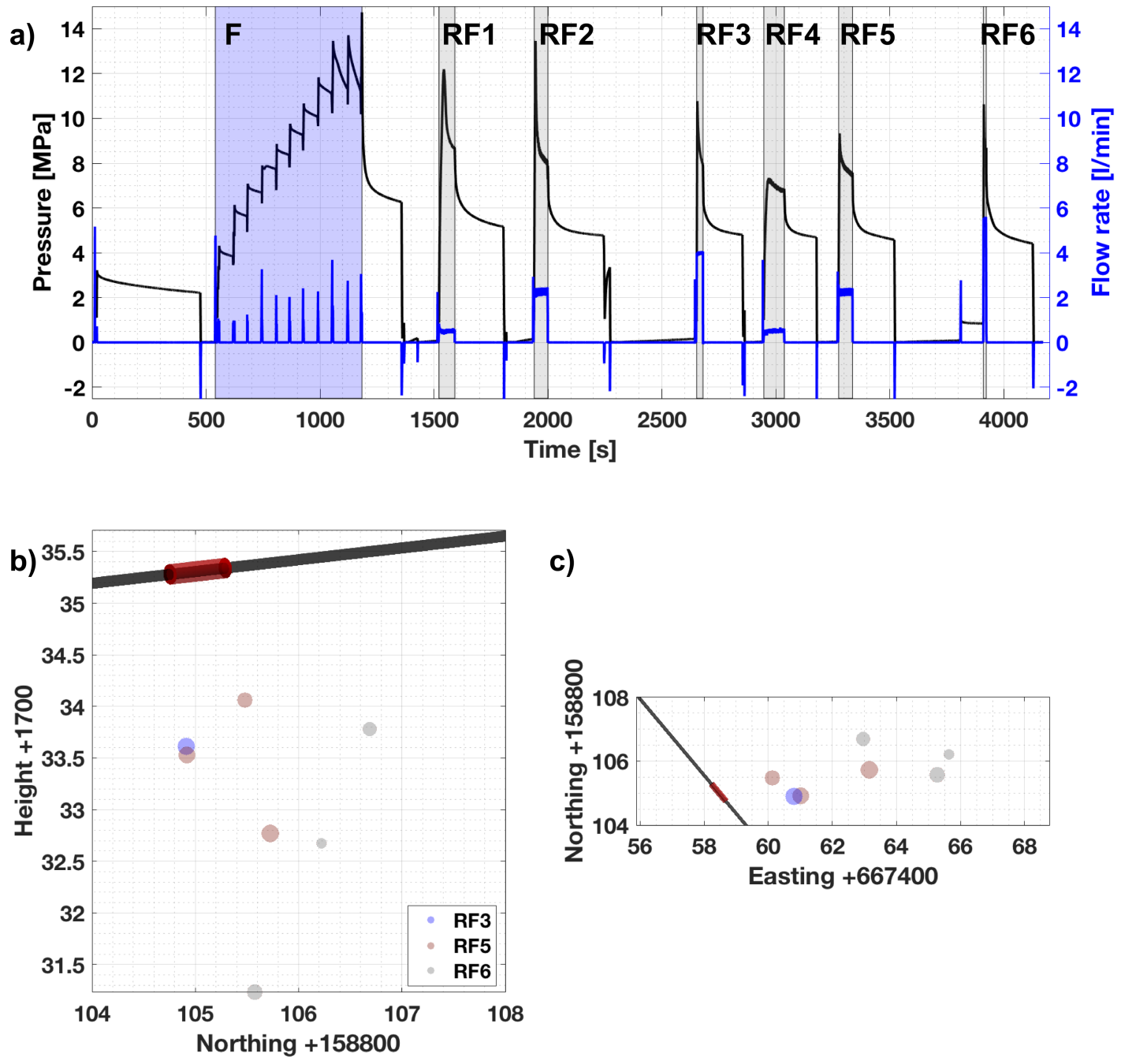

c)
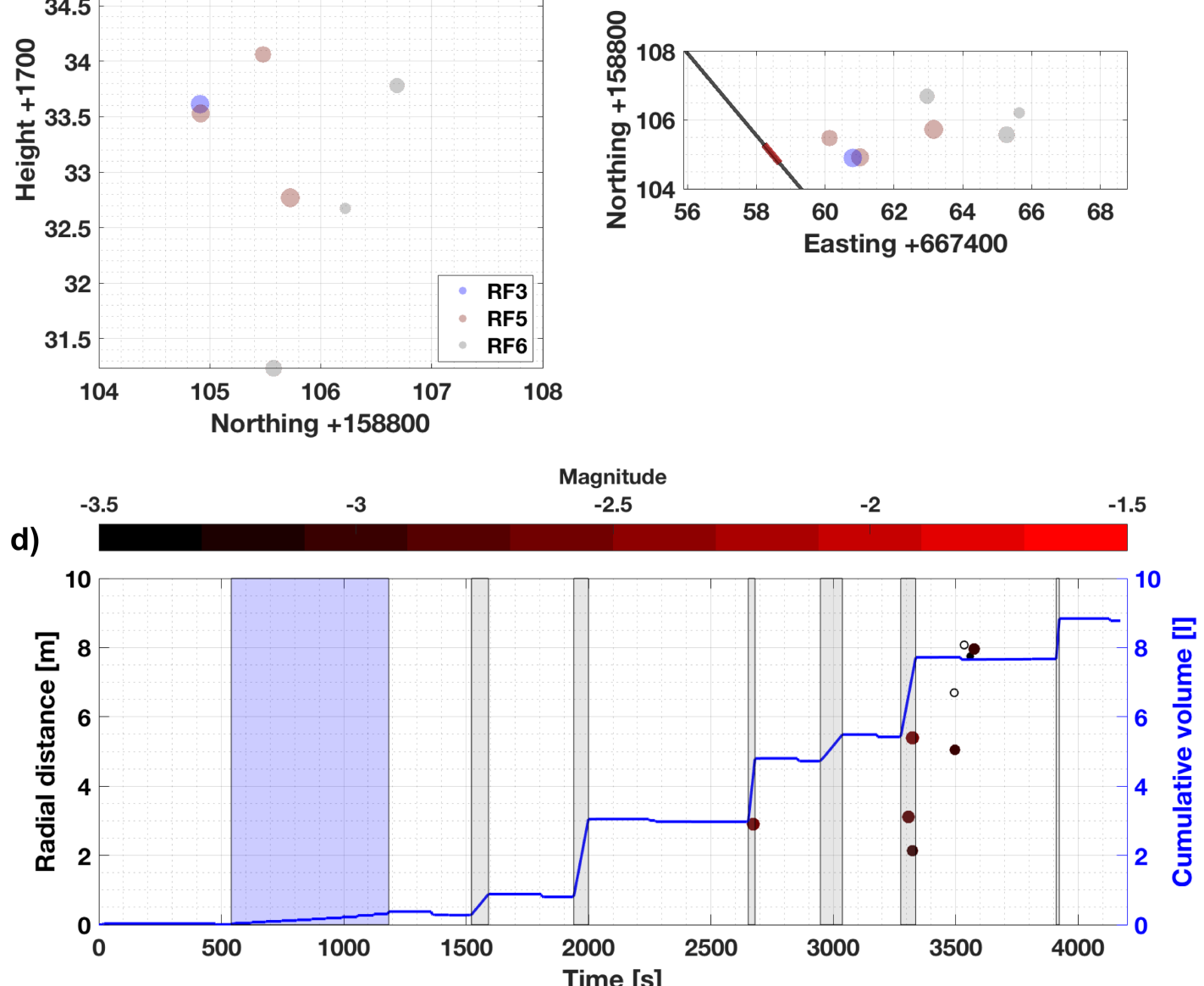

Figure S18: a) Injection pressure [MPa] and flow rate [1/min] are indicated for MF6 with blue shaded box during fluid pulse injection and gray shaded boxes for constant fluid injection. The overview of the located seismic events is presented in plane (b) and profile view (c). d) The radial distance from the injection interval to the seismic event is presented and the magnitude is indicated by color code. The cumulative injection volume is presented by blue solid line. 
MF7

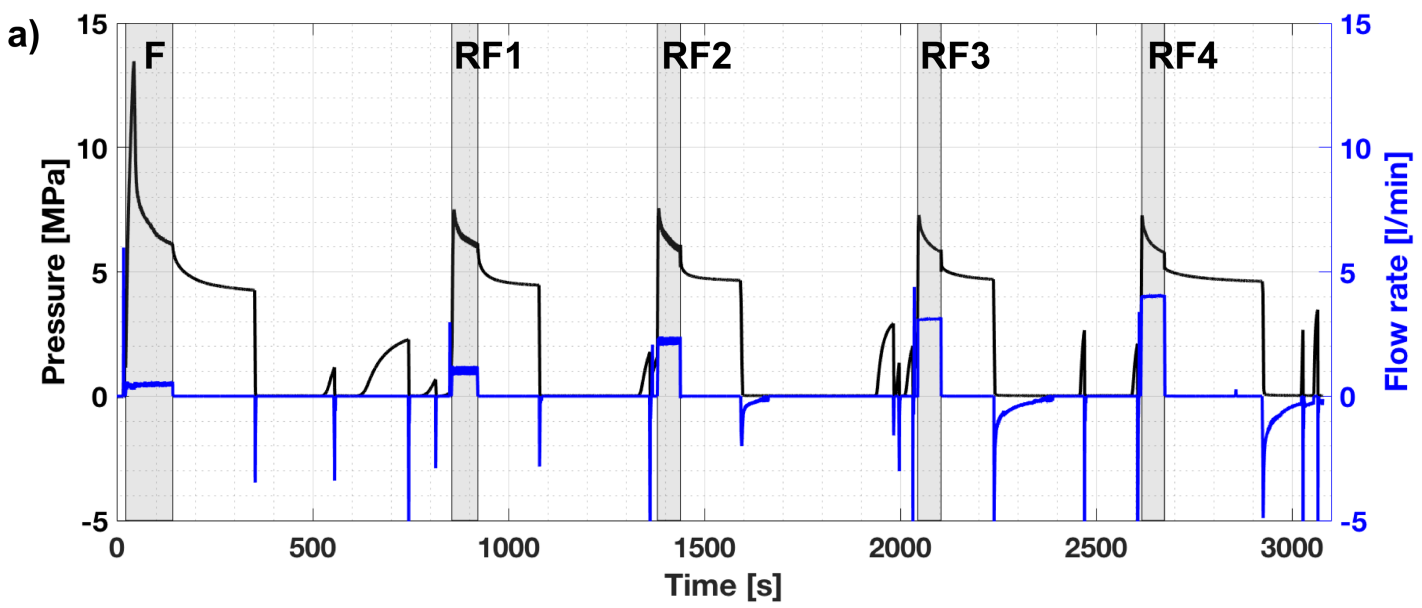

b)

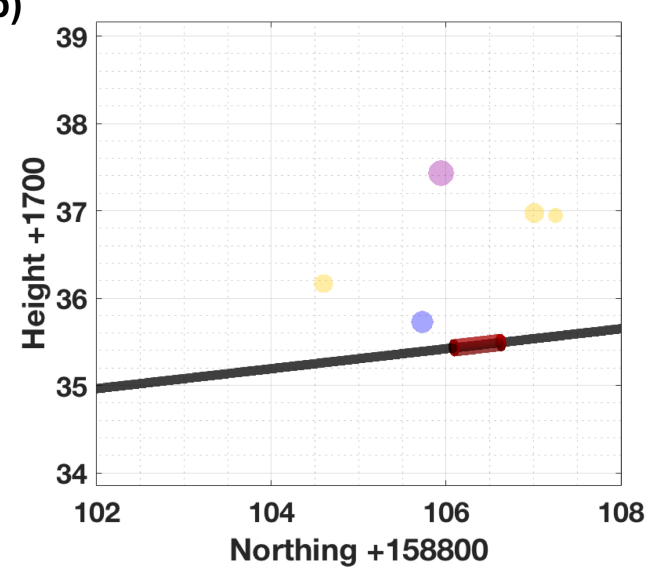

c)

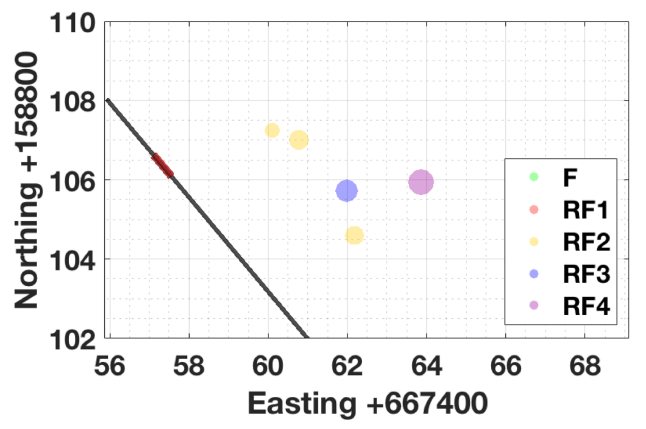

d)
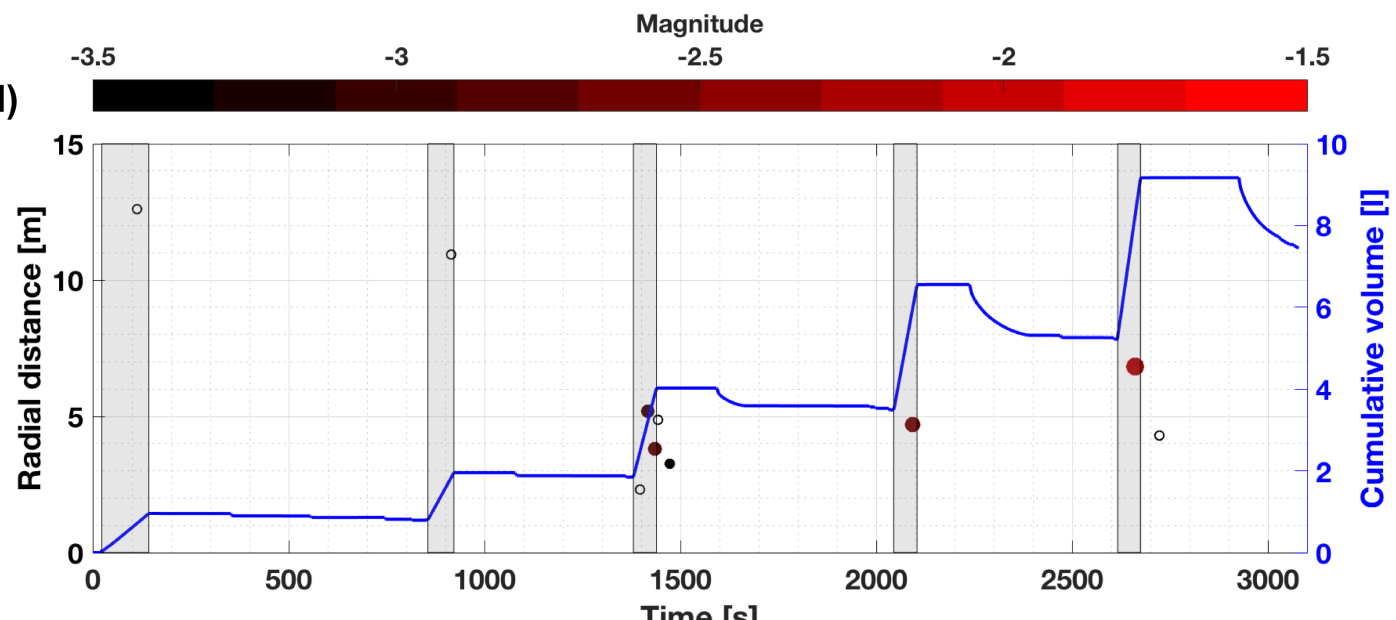

Figure S19: a) Injection pressure [MPa] and flow rate [1/min] are indicated for MF7 with gray shaded boxes during fluid injection. The overview of the located seismic events is presented in plane (b) and profile view (c). d) The radial distance from the injection interval to the seismic event is presented and the magnitude is indicated by color code. The cumulative injection volume is presented by blue solid line. 


\section{S7: References}

Doe, T. W., \& Korbin, G. E. (1987). A Comparison Of Hydraulic Fracturing And Hydraulic Jacking Stress Measurements. The 28th U.S. Symposium on Rock Mechanics (USRMS), 283-290.

Gischig, V. S., Doetsch, J., Maurer, H., Krietsch, H., Amann, F., Evans, K. F., ... Giardini, D. (2018). On the link between stress field and small-scale hydraulic fracture growth in anisotropic rock derived from microseismicity. Solid Earth, 9(1), 39-61. https://doi.org/10.5194/se-9-39-2018

Haimson, B. C., \& Cornet, F. (2003). ISRM Suggested Methods for rock stress estimation Part 3: hydraulic fracturing (HF) and/or hydraulic testing of pre-existing fractures (HTPF). Int. J. of Rock Mechanics and Mining Science, 40, 1011-1020.

Hartmaier, H. H., Doe, T. W., \& Dixon, G. (1998). Evaluation of Hydrojacking Tests for an Unlined Pressure Tunnel. Tunnelling and Underground Space Technology, 13(4), 393401.

Jalali, M., Gischig, V., Doetsch, J., Näf, R., Krietsch, H., Klepikova, M., ... Giardini, D. (2018). Transmissivity Changes and Microseismicity Induced by Small-scale Hydraulic Fracturing Tests in Crystalline Rock. Geophysical Research Letters, 45. https://doi.org/10.1002/2017GL076781

Klee, G. (2015). Hydraulic-Fracturing and HTPF - tests in borehole Nos SB 15.001, SB 15.003 and SB 15.004, Grimsel test site: In-Situ Stimulation and Circulation (ISC) - Project. Retrieved from https://doi.org/10.3929/ethz-b-000256665

Näf, R. (2017). Microseismic monitoring of hydrofractures in crystalline rock. MSc thesis, ETH Zurich.

Rutqvist, J., \& Stephansson, O. (1996). A cyclic hydraulic jacking test to determine the in situ stress normal to a fracture. International Journal of Rock Mechanics and Mining Sciences and Geomechanics, 33(7), 695-711. https://doi.org/10.1016/01489062(96)00013-7 